\title{
HDlive in the Assessment of Fetal Intracranial, Intrathoracic and Intra-abdominal Anomalies
}

\author{
${ }^{1}$ Sarah Cajusay-Velasco, ${ }^{2}$ Toshiyuki Hata
}

\begin{abstract}
We present a series of images of different fetal intracranial, intrathoracic and intra-abdominal anomalies reconstructed using HDlive. It is a novel three-dimensional (3D) ultrasound modality that can provide the operator with naturally realistic features of any fetal anomalies. HDlive and its inversion mode are applied in several cases and two-dimensional (2D) sonographic images of different anomalies are also presented clearly to compare the advantages of HDlive in this article. This review focuses on the role of HDlive in the presence of such anomalies. HDlive should be a very useful aid in adjunct to other ultrasound modalities, specifically in cases that warrant detailed information. It can also be useful for the antenatal surveillance of anomalies, such as cystic lesions that may progress to complications. This innovative tool offers many promising advantages in clinical practice and future research on fetal anomalies.
\end{abstract}

Keywords: 2D ultrasound, 3D ultrasound, Inversion mode, HDlive, Fetus, Intracranial anomaly, Intrathoracic anomaly, Intra-abdominal anomaly.

How to cite this article: Cajusay-Velasco S, Hata T. HDlive in the Assessment of Fetal Intracranial, Intrathoracic and Intraabdominal Anomalies. Donald School J Ultrasound Obstet Gynecol 2014;8(4):362-375.

Source of support: Nil

Conflict of interest: None

\section{INTRODUCTION}

One of the most important concerns of physicians and patients during pregnancy is the occurrence of any fetal anomalies. Congenital anomalies occur in 1 in 33 infants, and it is one of the commonest causes of high neonatal mortality. ${ }^{1}$ Early detection during the antenatal period is very significant.

Ultrasound is one of the recommended antenatal screening tools for fetal anomalies. Different modalities have evolved that aid in clinical practice and research.

\footnotetext{
${ }^{1}$ Research Fellow, ${ }^{2}$ Professor and Chairman

${ }^{1,2}$ Department of Perinatology and Gynecology, Kagawa University Graduate School of Medicine, Kagawa, Japan

Corresponding Author: Toshiyuki Hata, Professor and Chairman, Department of Perinatology and Gynecology, Kagawa University Graduate School of Medicine, 1750-1 Ikenobe, Miki Kagawa 761-0793, Japan, Phone: +81-0878912174, e-mail: toshi28@med.kagawa-u.ac.jp
}

Recent advances have been focused on improving threedimensional (3D) and four-dimensional (4D) sonographic findings. The latest technology in ultrasonography is the use of High Definition live (HDlive). It has software that calculates the propagation of light and a virtual light source that can be adjusted, producing lighting and shadowing effects. ${ }^{2}$ These effects increase depth perception and, with the availability of different shades of skin-like color, images are more realistic in appearance. ${ }^{3}$ It has several types of rendering software that can be used depending on the structures to be studied. The HDlive surface-rendering mode has been used for visualization in many studies of normal and abnormal fetal structures. ${ }^{2-10}$ The surface of the area of interest is best visualized in the presence of adequate amniotic fluid. The most commonly evaluated structures using the surface-rendering mode are facial abnormalities. Another technique is the use of HDlive with an inversion mode. It uses a threshold filter tool to produce a satisfactory volume set where the fluid-filled structures become transparent, and the application of the inversion mode will transform this into a cast-like structure. ${ }^{11}$ It improves visualization and the understanding of spatial relationships between fluid-filled fetal structures such as the brain vesicles and the fetal heart. ${ }^{11}$ It can also used in the study of scattered fluid-filled spaces, such as pleural effusion. ${ }^{11}$

This review article presents different intracranial, intrathoracic and intra-abdominal anomalies reconstructed using HDlive and its inversion mode and, based on them, makes recommendations for antenatal diagnosis, surveillance and future research.

\section{FETAL INTRACRANIAL ANOMALY}

The fetal intracranial structures should be thoroughly evaluated during antenatal sonographic examinations because the occurrence of anomalies often leads to severe perinatal outcomes. Abnormal development in the early stage of pregnancy can be recognized by conventional two-dimensional (2D) ultrasonography. Beginning at 10 to 14 weeks of gestation, screening for congenital anomalies is initially performed. ${ }^{12}$ One of the earliest intracranial anomalies that can be detected during this period is acrania/exencephaly. Such 2D sonographic findings are helpful but have some limitations for 
further clinical studies because patients might not fully understand the black and white images of their fetus and its abnormality. With the advent of the latest ultrasound technologies, the fetal brain and vesicles can be studied as at early as 7 weeks of gestation. ${ }^{13}$ Most of the intracranial anomalies are now observable in detail. These fetal intracranial anomalies are reevaluated and reconstructed using HDlive.

\section{Brain Vesicle Early in the First Trimester}

The embryonic brain vesicles are presented to become familiarized with the normal anatomical structures in early pregnancy. In the 4th week of gestation, the neural tube will give rise to the prosencephalon, mesencephalon and rhombencephalon. In the 5th week, it will develop into five secondary brain vesicles, which are the telencephalon, diencephalon, mesencephalon, metencephalon and myelencephalon. ${ }^{13}$ As early as in the 7th week of gestation, 2D sonographic images show that the brain vesicles are anechoic, irregular

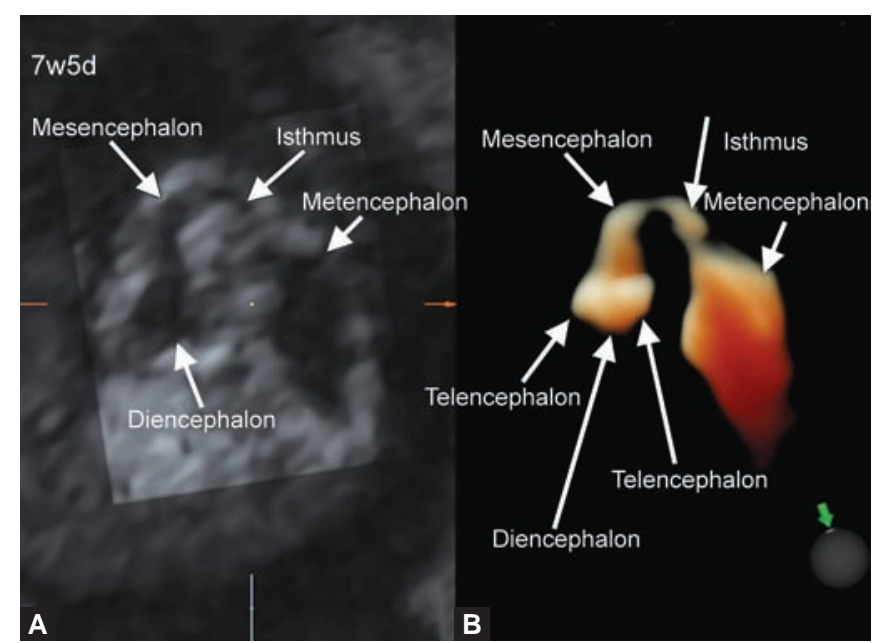

Figs 1A and B: HDlive image of developing brain vesicles using the inversion mode in a normal embyo at 7 weeks and 5 days of gestation: (A) two-dimensional sonographic sagittal image and (B) HDlive image
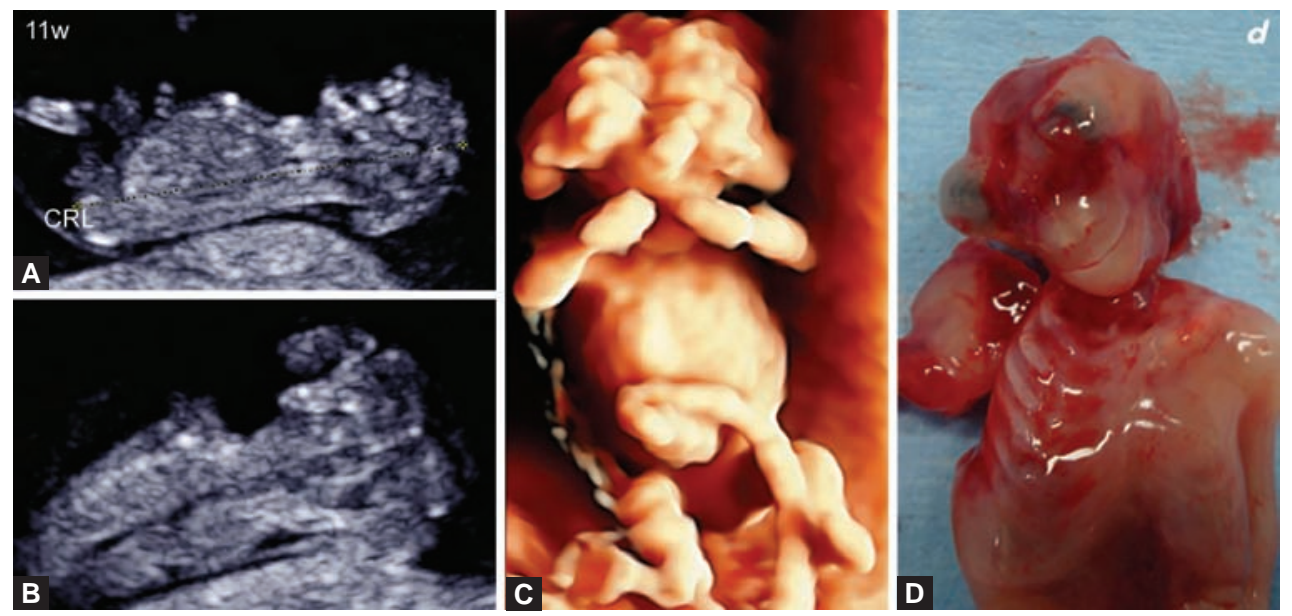

Figs 3A to D: HDlive image of a fetus with acrania/exencephaly at 11 weeks of gestation: $(A$ and $B)$ two-dimensional sonographic images, (C) HDlive image and (D) photograph of the abortus structures (Fig. 1A). The HDlive inversion mode can depict the tiny lobulated telencephalon, diencephalon, and mesencephalon but the demarcation is not welldefined, and the metencephalon appears as an elongated structure (Fig. 1B). In the 8 th weeks of gestation, brain vesicles are more discernible using HDlive. The telencephalon appears as a pair of rounded structures, the diencephalon and mesencephalon are still not well-differentiated, the isthmus is thin, metencephalon becomes rounded, and the myelencephalon appears as a small elongated structure (Fig. 2). These HDlive images can be used as a reference for early fetal anomalies such as holoprosencephaly and ventriculomegaly.

\section{Acrania/Exencephaly}

Acrania/exencephaly is diagnosed when there is cranial vault absence with exposed brain tissue. ${ }^{12}$ At 11 weeks of gestation, 2D sonography shows the characteristic appearance which is the 'Mickey Mouse sign' (Figs 3A and $\mathrm{B})$. The appearance of the fetus with acrania/

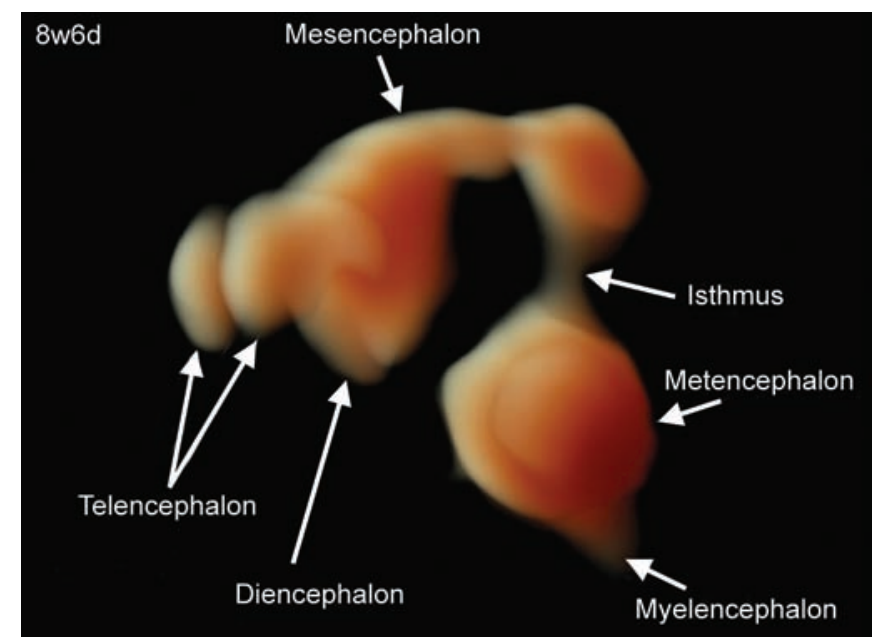

Fig. 2: HDlive image of developing brain vesicles using the inversion mode in a normal embryo at 8 weeks and 6 days of gestation 


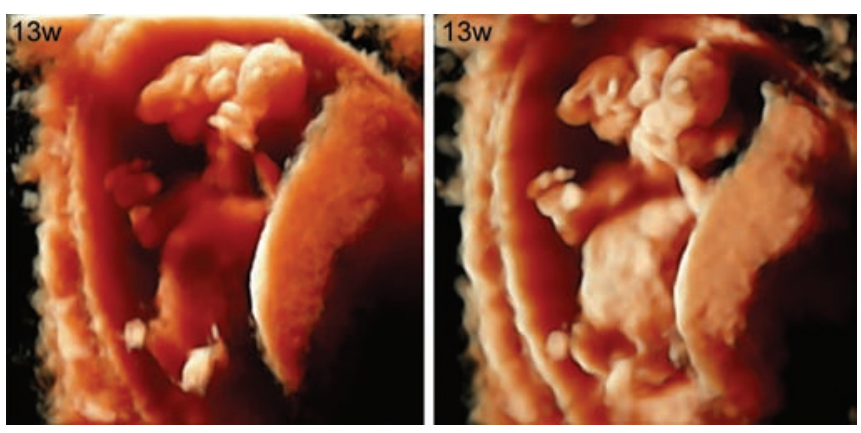

Fig. 4: HDlive images with different light sources of a fetus with acrania/exencephaly at 13 weeks of gestation (Courtesy: Reprinted with permission from Hata T et al) $)^{8}$

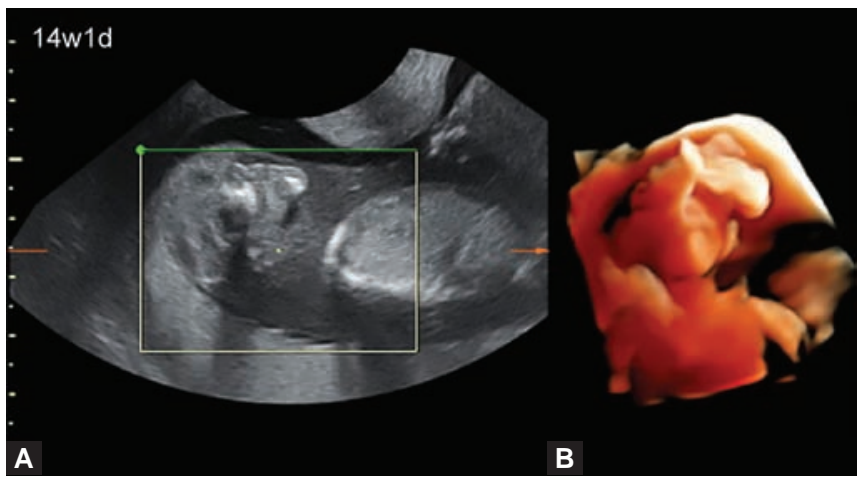

Figs 5A and B: HDlive image of a fetus with acrania/exencephaly at 14 weeks and 1 day of gestation: (A) two-dimensional sonographic image and (B) HDlive image
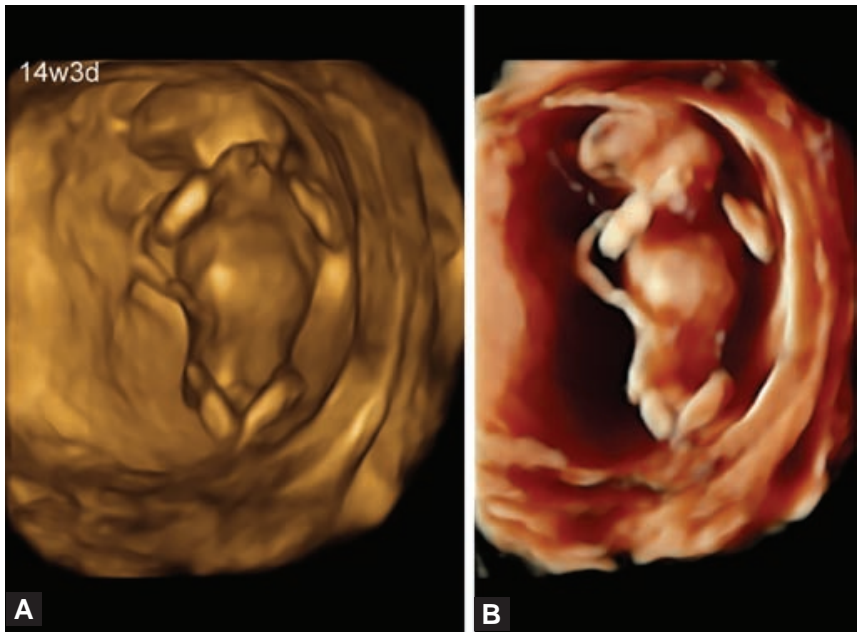

Figs 6A and B: A fetus with acrania/exencephaly at 14 weeks and 3 days of gestation: (A) conventional three-dimensional ultrasound image and (B) HDlive image

exencephaly in an HDlive image (Fig. 3C) is similar to the actual picture of the abortus (Fig. 3D). Another case of acrania/exencephaly at 13 weeks of gestation also clearly shows the deformed and degenerated brain tissues (Fig. 4). ${ }^{8}$ The echogenic structure in 2D sonography that yields the 'Mickey Mouse sign' appearance (Fig. 5A) is clearly visible in HDlive image as the exposed fetal brain tissues (Fig. 5B). Conventional 3D sonography can also provide a good image of acrania/exencephaly (Fig. 6A) but the skin-like color effect on HDlive provides a more realistic human appearance (Fig. 6B).

\section{Choroid Plexus Cyst}

It is a rare intracranial structure, most commonly seen in the lateral ventricles. ${ }^{14}$ The findings of a choroid plexus cyst with other sonographic abnormalities is associated with aneuploidy, particularly trisomy $18 .{ }^{15}$ However, a single, isolated cyst does not increase the risk, and it usually disappears before 26 weeks of gestation. ${ }^{15}$ On 2D sonography, bilateral choroid plexus cysts can be observed as rounded, sonoluscent structures (Fig. 7A). With HDlive, the rounded mass can be clearly seen in the posterior horn of the lateral ventricles, distinctly separate from other structures (Fig. 7B). The smooth inner surface is also clearly recognized.

\section{Hydrocephalus}

Obstructions at any point of the ventricular system will cause ventriculomegaly. ${ }^{16}$ On HDlive, the choroid plexus is well-defined, dangling on the widened lateral ventricle (Figs 8A to C). Worsening of the condition will lead to hydrocephalus (Fig. 9A). Diagnosis of severe hydrocephalus on 2D sonography is made when there is scalloping of frontal bones or the 'lemon sign' on transverse view (Fig. 9B). ${ }^{12}$ While the finding of 'banana sign' is due to posterior displacement of the cerebellum on the occipital bone (Fig. 9C). ${ }^{12}$ These findings are usually accompanied by vertebral myelomeningocele (Fig. 9D). ${ }^{17}$ Using the HDlive inversion mode, the dilatation of the ventricular system can be clearly noted. Anatomical parts of the lateral ventricle from the anterior to posterior horn are clearly identifiable (Figs 10A to C).

\section{Cerebellar Hypoplasia}

Anomalies of the cerebellum occur in many types of aneuploidy. ${ }^{18}$ A normal 2D sonographic image of a cerebellum at 20 to 21 weeks of gestation appears as an echogenic, rounded structure with fissures or folds known as folia. ${ }^{18}$ The absence of these structures may indicate cerebellar hypoplasia. An HDlive image can show the features of underdeveloped cerebellar hemispheres. The sizes are different, and the contours are not well-defined (Fig. 11). Undeveloped cerebellar hemispheres including the structure dividing it are known as cerebellar vermian hypoplasia. On 2D sonography, the vermis, which is an echogenic structure, and appears along the entire length of the paired cerebellum, cannot be observed (Fig. 12A). HDlive shows two cerebellar hemispheres, and the vermis appears thin and short between bilateral hemispheres (Fig. 12B). 


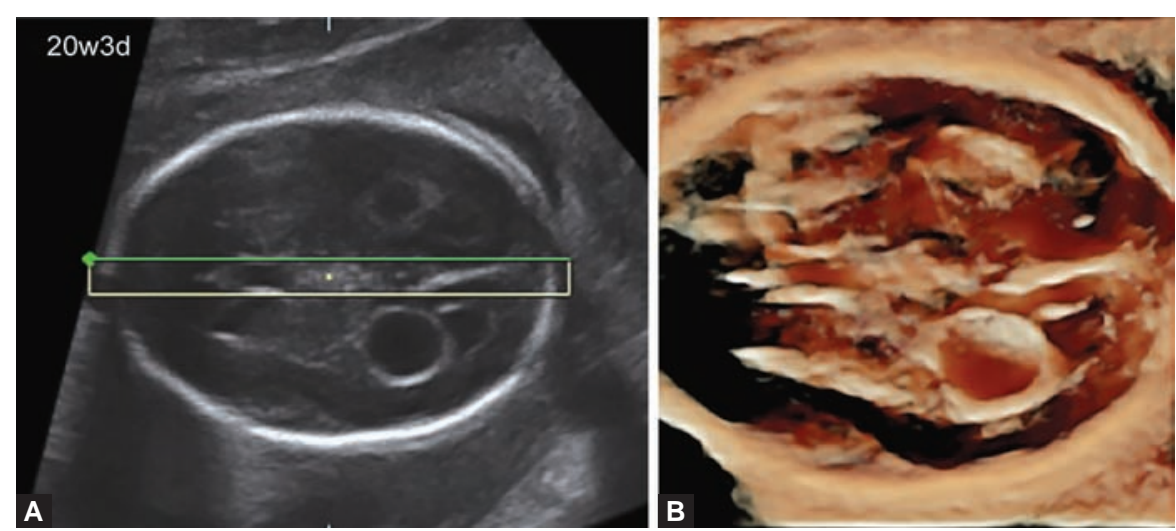

Figs 7A and B: HDlive image of a bilateral choroid plexus cyst at 20 weeks and 3 days of gestation: (A) two-dimensional sonographic image and (B) HDlive image
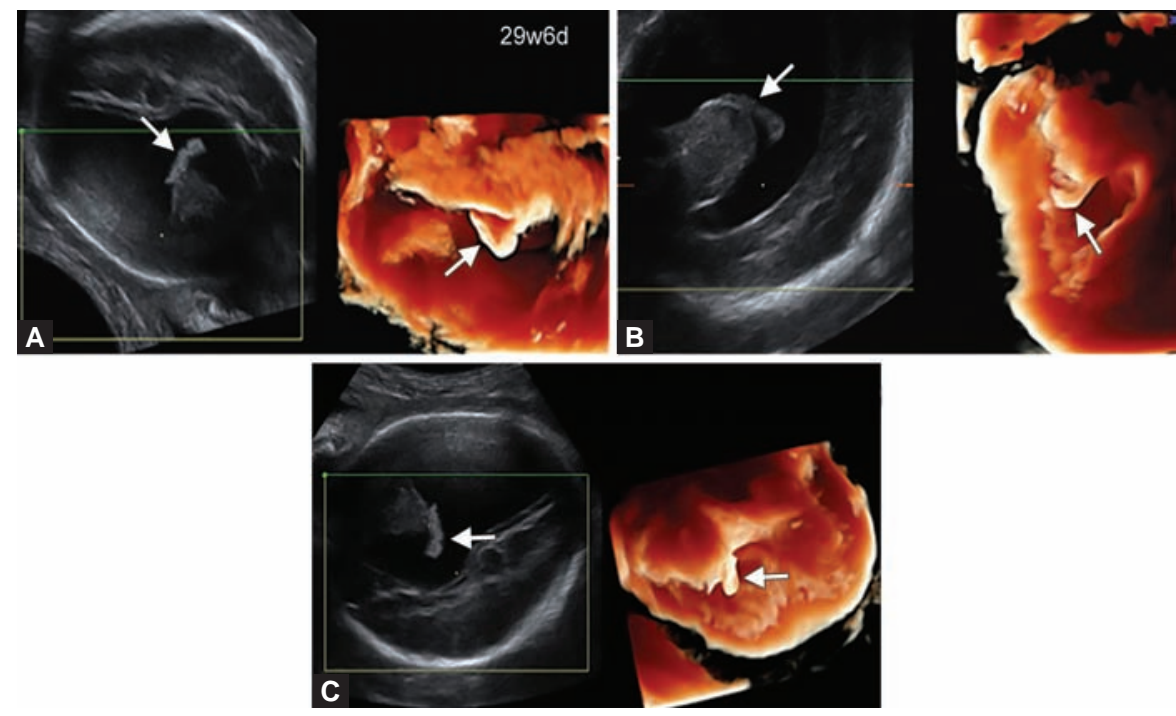

Figs 8A to C: HDlive images of unilateral ventriculomegaly at 29 weeks and 6 days of gestation. The choroid plexus is shown in different views (arrows)
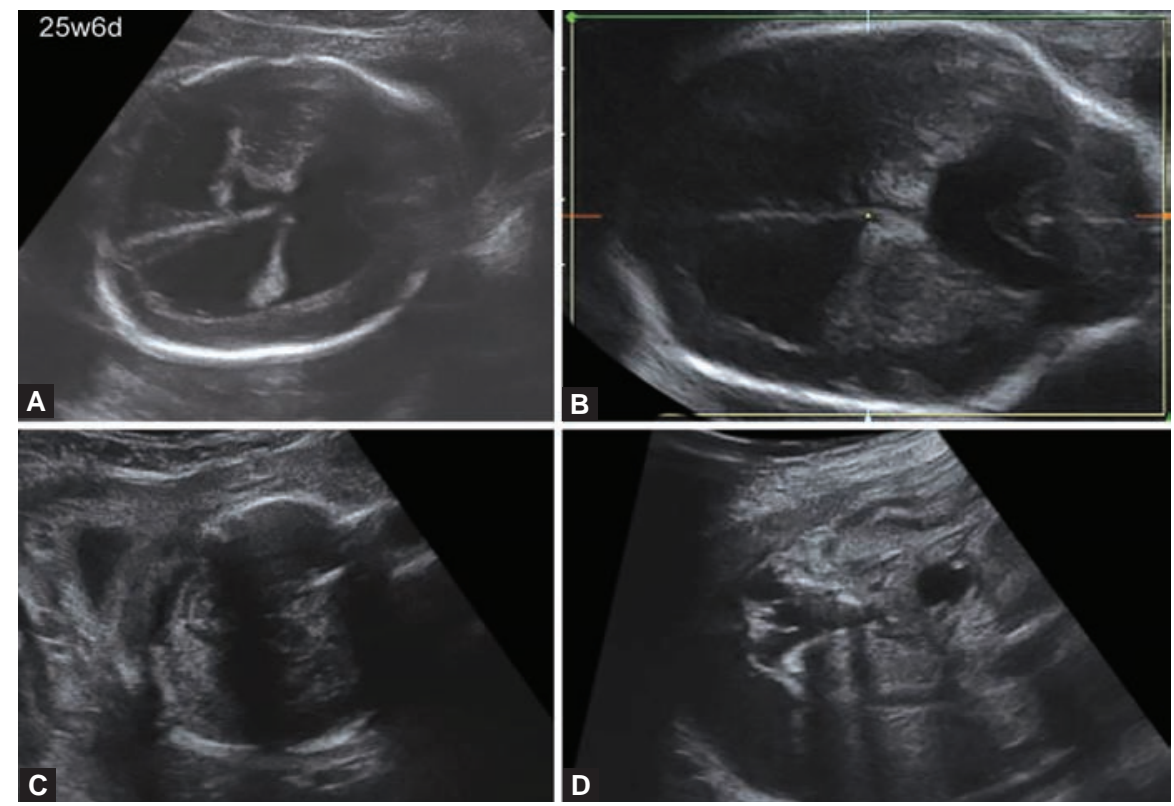

Figs 9A to D: Two-dimensional sonographic images of a fetus with hydrocephalus and sacral myelomeningocele at 25 weeks and 6 days of gestation. The dilated ventricles are evident (A). 'Lemon sign' (B) and 'Banana sign' (C) are characteristics of hydrocephalus, which is usually associated with myelomeningocele (D) 

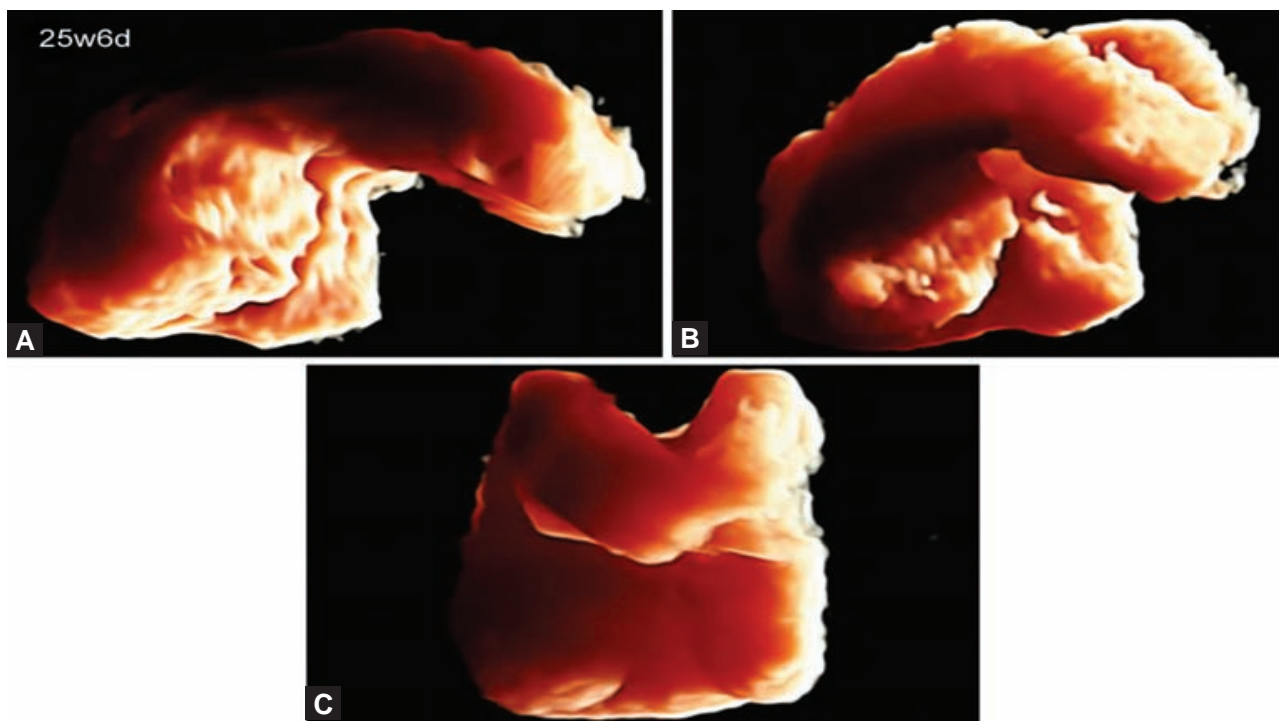

Figs $10 \mathrm{~A}$ to $\mathrm{C}$ : HDlive images of a lateral ventricle using the inversion mode in a fetus with hydrocephalus and sacral myelomeningocele at 25 weeks and 6 days of gestation. (A) lateral view, (B) right oblique view, (C) frontal view

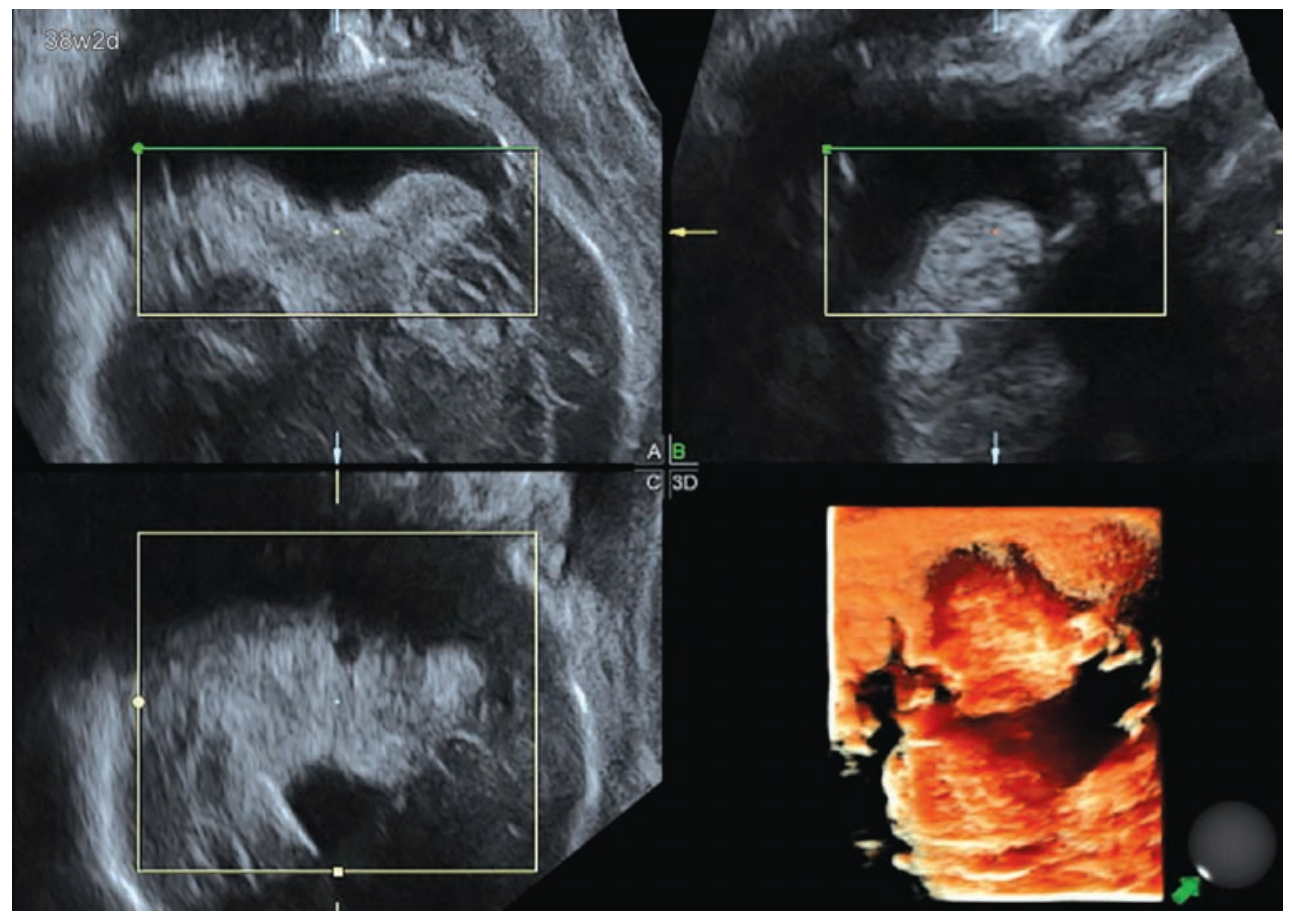

Fig. 11: Three-dimensional multiplanar view and HDlive image of cerebellar hypoplasia in a trisomy 18 fetus at 38 weeks and 2 days of gestation

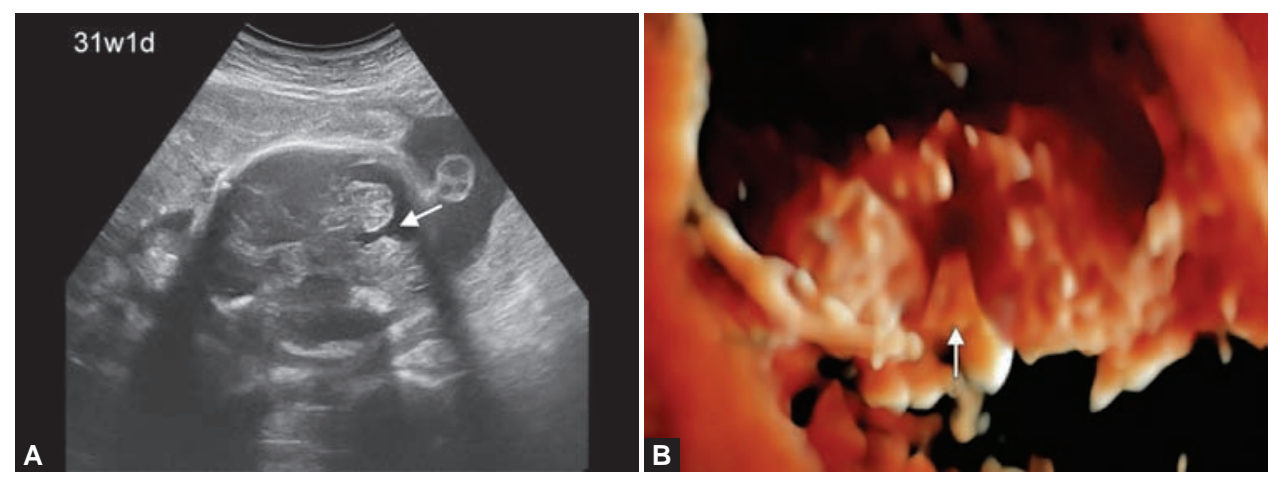

Figs 12A and B: HDlive image of cerebellar vermian hypoplasia (arrows) in a trisomy 13 fetus at 31 weeks and 1 day of gestation: (A) two-dimensional sonographic image and (B) HDlive image 


\section{Myelomeningocele}

A huge protruding mass overlying the vertebral defect on the sacral region is clearly evident on HDlive (Fig. 13). The spinal cord is also visible.

\section{FETAL INTRATHORACIC ANOMALY}

Evaluation of the fetal intrathoracic region involves two important structures, the heart and lungs. Anomalies of these major structures may lead to serious complications. Clinical studies are usually focused on the fetal heart using recent advances in fetal echocardiography. HDlive and its inversion mode offer a better understanding of the fetal heart and its adjacent structures that will help clinicians in diagnosis and management.

\section{Pericardial Effusion}

One of the commonest complications of intrathoracic anomaly is pericardial effusion that occurs in the presence of congestive heart failure. A 2D sonographic image shows the sonoluscent area containing an increased amount of fluid (Fig. 14A). On HDlive, the pericardium of the left and right atrium is identified. The widened pericardial space is due to excessive fluid accumulation (Fig. 14B). Mediastinal shift of the heart to the right can be noted.

\section{Situs Inversus Totalis}

The 'mirror image', where the heart and abdominal viscera are located on the right side of the fetal body, is

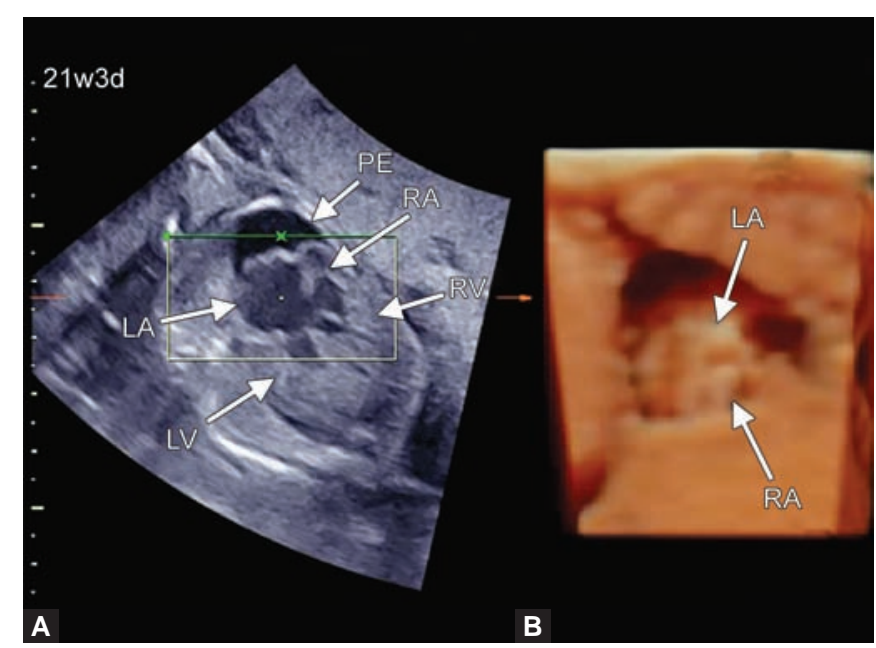

Figs 14A and B: HDlive image of a fetal thorax with pericardia effusion in a fetus with an endocardial cushion defect at 21 weeks and 3 days of gestation: (A) two-dimensional sonographic image and (B) HDlive image (LA: Left atrium; LV: Left ventricle; PE: Pericardial effusion; RV: Right ventricle; RA: Right atrium)

known as situs inversus totalis (Figs 15A and B).$^{19}$ Using the HDlive inversion mode, the thoracic and abdominal viscera are clearly seen in a reverse position (Fig. 16). The abnormal position of the left ventricle means the heart apex is located on the right. The aortic arch turns toward the right. The right ventricle is on the left, and the direction of the pulmonary artery is clearly identified. The mirror image of normal cardiac structures can be clearly recognized using the HDlive inversion mode. The stomach is also seen on the right.

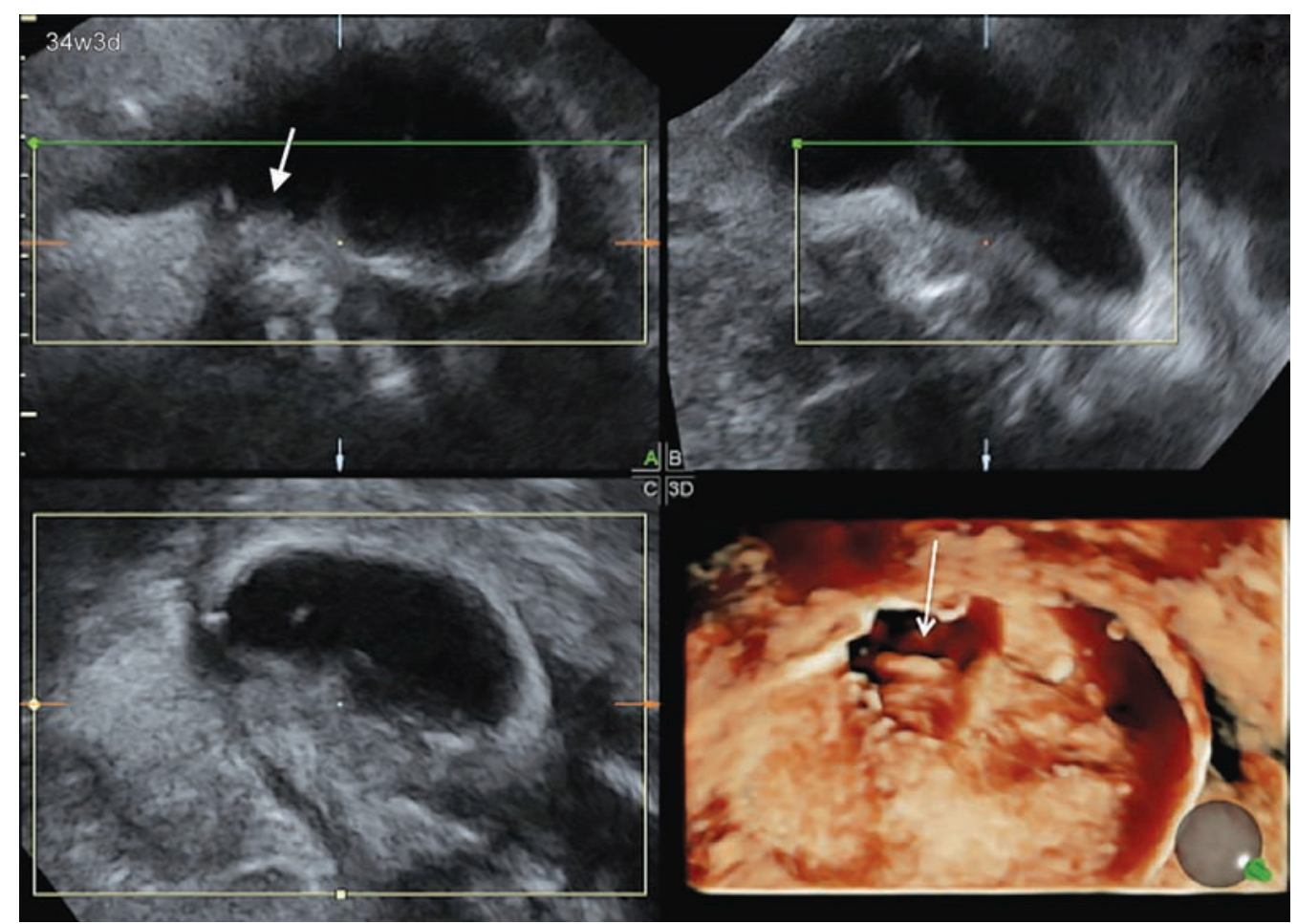

Fig. 13: Three-dimensional multiplanar view and HDlive image of sacral myelomeningocele at 34 weeks and 3 days. The spinal cord is identified (arrows) 

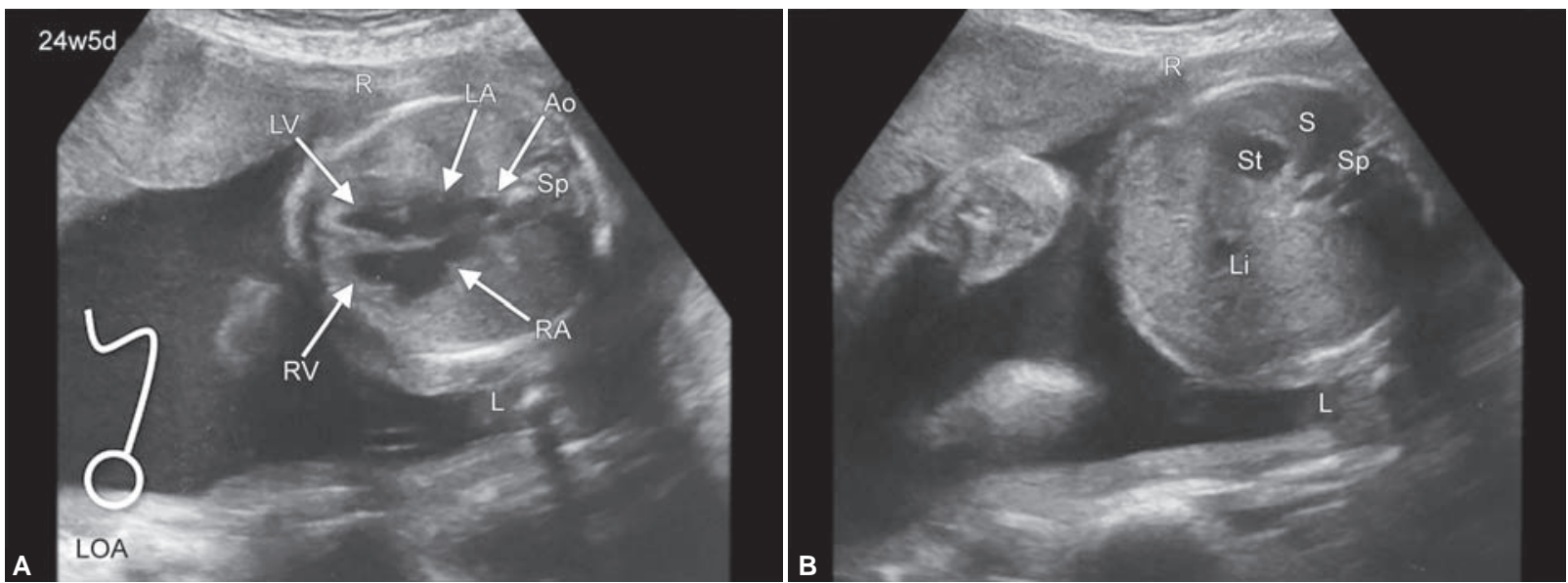

Figs 15A and B: Two-dimensional sonographic images of a fetus in a left occipito-anterior position (LOA) with situs inversus totalis at 24 weeks and 5 days of gestation: (A) two-dimensional sonographic image of the fetal thorax, (B) two-dimensional sonographic image of the fetal abdomen (Ao: Aorta; L: Left; LA: Left atrium; LV: Left ventricle; Li: Liver; R: Right; RA: Right atrium; RV: Right ventricle; S: Spleen; Sp: Spine; St: Stomach) (Courtesy: Reprinted with permission from Hata T, et al) ${ }^{19}$

\section{Diaphragmatic Hernia}

In diaphragmatic hernia, a portion of the body of the stomach is seen beside the heart in the thoracic area (Fig. 17A). The heart is displaced to the right, and the stomach is also in the thorax. The HDlive inversion mode clearly delineates the spatial relationship between the leftsided stomach and right-side-deviated normal cardiac structures (Fig. 17B).

\section{Pleural Effusion}

HDlive shows the left thoracic cavity with pleural effusion. The shrunken left lung is somewhat pushed medially due to excessive fluid in the left pleural cavity (Fig. 18).
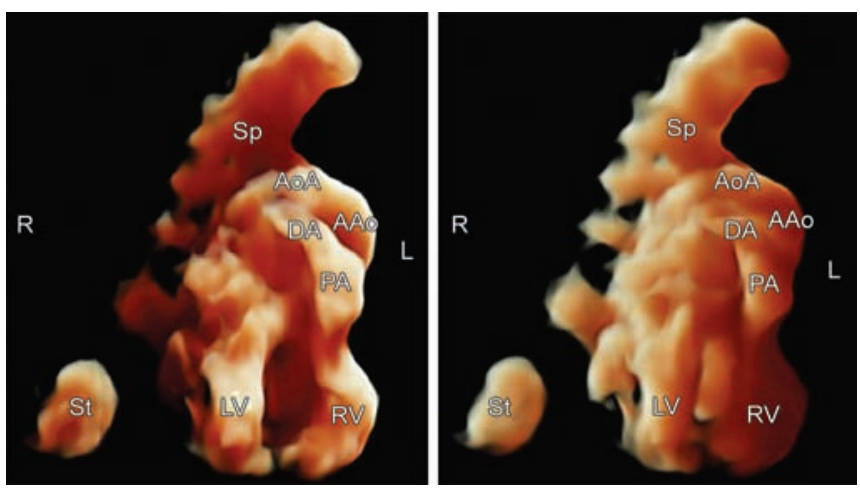

Fig. 16: HDlive images of a fetal chest and abdomen using the inversion mode and different light sources in a fetus with situs inversus totalis at 24 weeks and 5 days of gestation (AoA: Aortic arch; AAo: Ascending aorta; DA: Ductus arteriosus; L: Left LV: Left ventricle; PA: Pulmonary artery; R: Right; RV: Right ventricle; Sp: Spine; St: Stomach)

\section{FETAL INTRA-ABDOMINAL ANOMALY}

Malformations and cystic lesions are usual forms of fetal intra-abdominal anomalies. Most of these conditions are

benign but warrant strict surveillance because they may cause gradual or sudden complications. 2D sonographic images of abdominal cystic lesions are similar, and
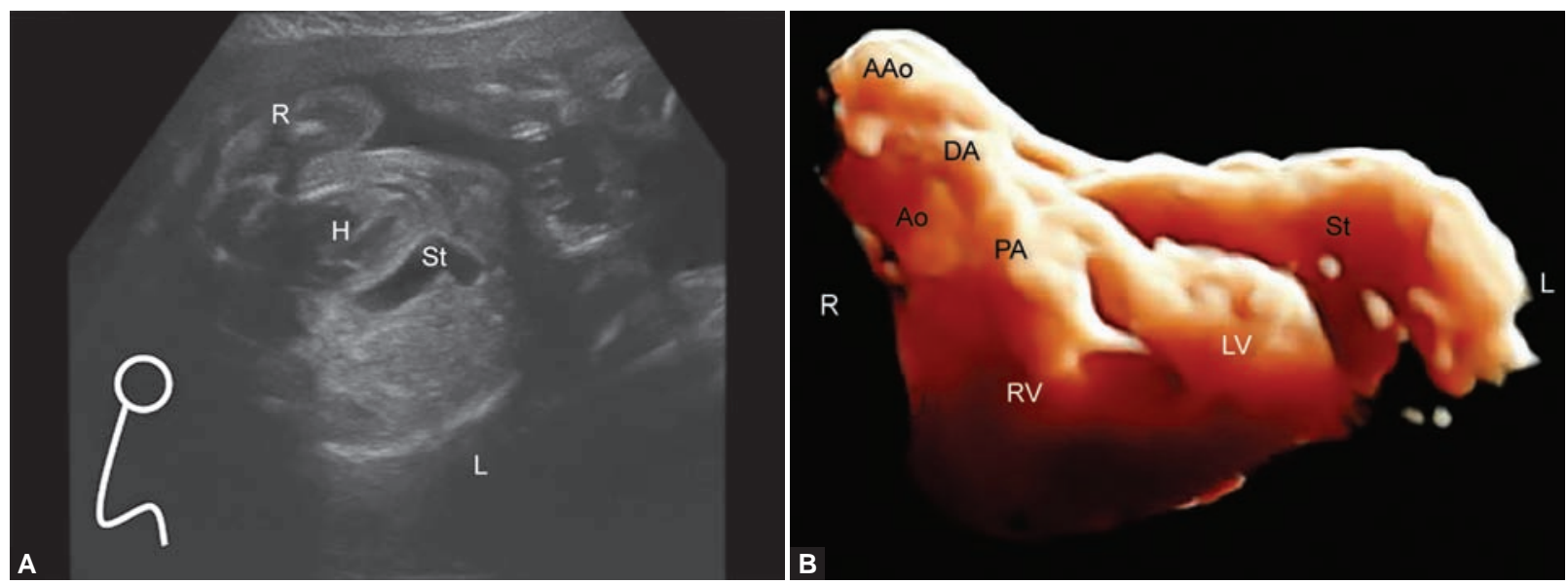

Figs 17A and B: HDlive image of a fetal thorax using the inversion mode in a fetus in the breech position with diaphragmatic hernia at 26 weeks of gestation: (A) two-dimensional sonographic image, (B) HDlive image (Ao: Aorta; AAo: Ascending aorta; DA: Ductus arteriosus; H: Heart; L: Left; LV: Left ventricle; PA: Pulmonary artery; R: Right; RV: Right ventricle; St: Stomach) 


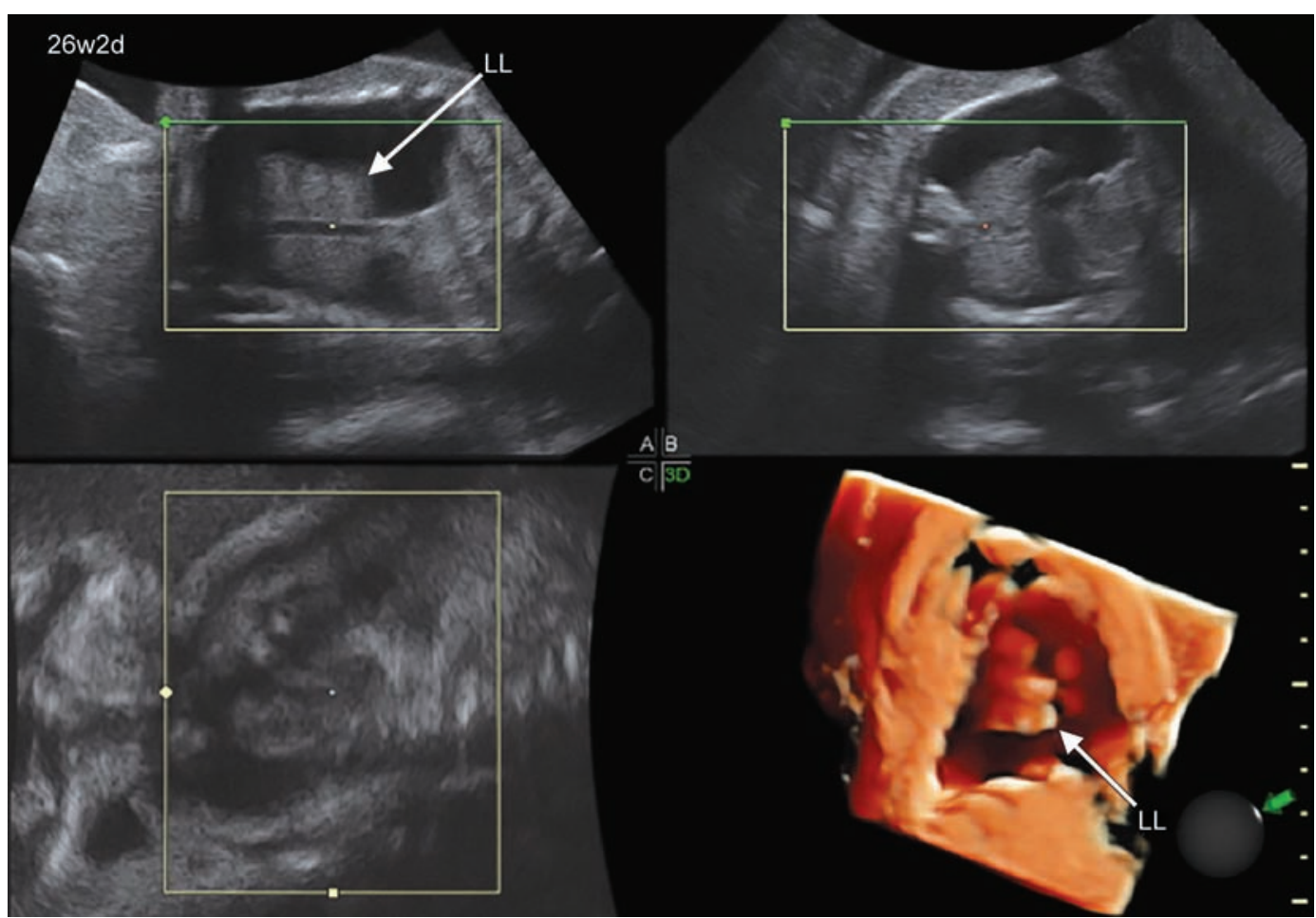

Fig. 18: Three-dimensional multiplanar view and HDlive image of a fetal lung with pleural effusion at 26 weeks and 2 days of gestation (LL: Left lung)

difficult to use to make a particular diagnosis. With HDlive and its inversion mode, the characteristics of each lesion and their anatomical relationships with other intraabdominal structures can be clearly visualized.

\section{Biliary Atresia}

A 2D sonographic image shows a connection between the gallbladder and cyst (Fig. 19). ${ }^{20}$ The HDlive inversion mode shows the anatomical relationship of the oval cyst that is connected with the gallbladder, indicating that a solid or blocked cystic duct in-between is present

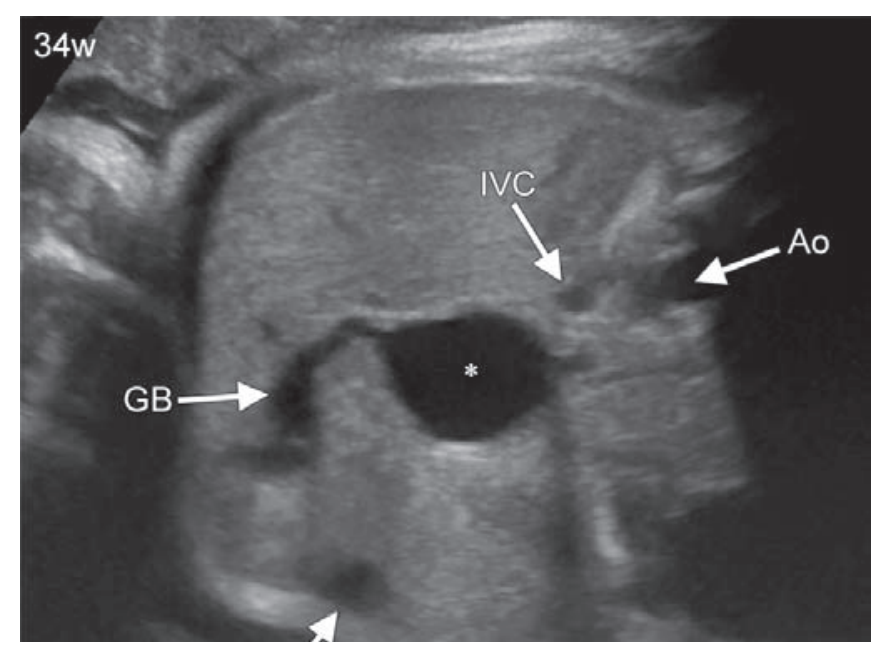

Fig. 19: Two-dimensional sonographic image of a fetal abdomen with biliary atresia $\left(^{*}\right)$ at 34 weeks of gestation (Ao: Aorta; GB: Gallbladder; IVC: Inferior vena cava; UV: Umbilical vein) (Courtesy: Reprinted with permission from Hata T, et al) ${ }^{20}$
(Fig. 20). The relationship of the cyst with other fluid-filled structures, such as the bladder and umbilical vein, can also be identified. The HDlive surface-rendering mode shows the inner surface of the cyst which is smooth, and contains some debris (Fig. 21).

\section{Enteric Duplication Cyst}

It is a rare cystic lesion usually located in the small intestine, particularly in the ileus. ${ }^{21} 2 \mathrm{D}$ sonography shows a thick-walled cyst with heterogeneous internal echoes (Fig. 22A). ${ }^{21}$ HDlive provides a more discernible image of a rounded structure with a thick wall, no communication with other intra-abdominal structures, and presence of large amounts of thick debris inside which can be visualized with conventional 2D sonography (Fig. 22B). ${ }^{21}$ This collection of thick debris is due to the necrosis of internal mucosa from gradual torsion of the cyst causing intestinal obstruction in utero.

\section{Ovarian Cyst}

The multiplanar 3D view shows a rounded cyst near the bladder (Fig. 23A). HDlive demonstrates the relatively smooth surface inside the cyst (Fig. 23B). The HDlive inversion mode further presents the anatomical relationship of the ovarian cyst, bladder, and other structures such as the renal pelvis and stomach (Fig. 24). 

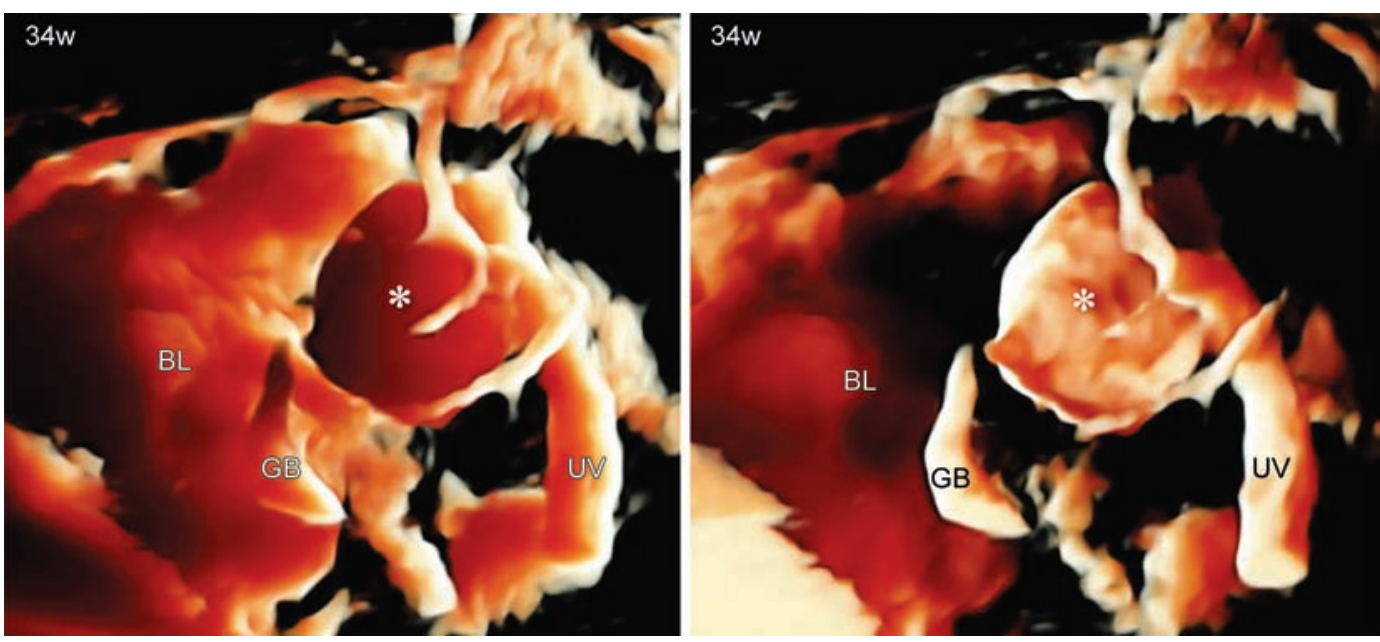

Fig. 20: HDlive images of a fetal abdomen using the inversion mode and different light sources in a fetus with biliary atresia (*) at 34 weeks of gestation (BL: Bladder; GB: Gallbladder; UV: Umbilical vein)
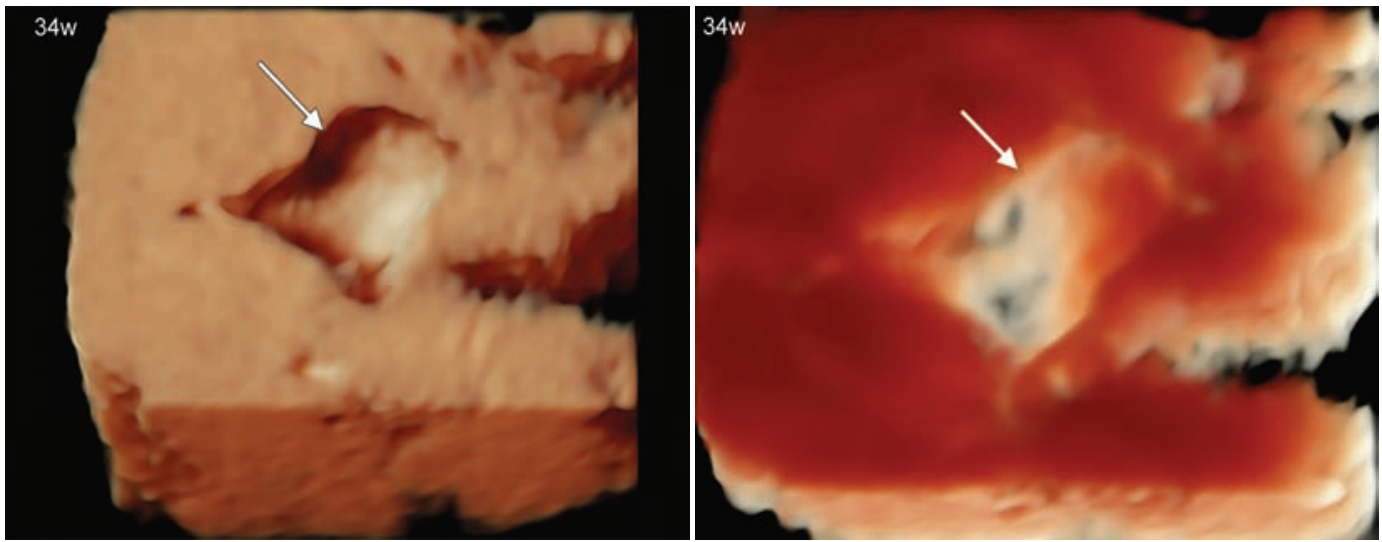

Fig. 21: HDlive images with different light sources of biliary atresia showing the inner surface of the cyst (arrows) at 34 weeks of gestation
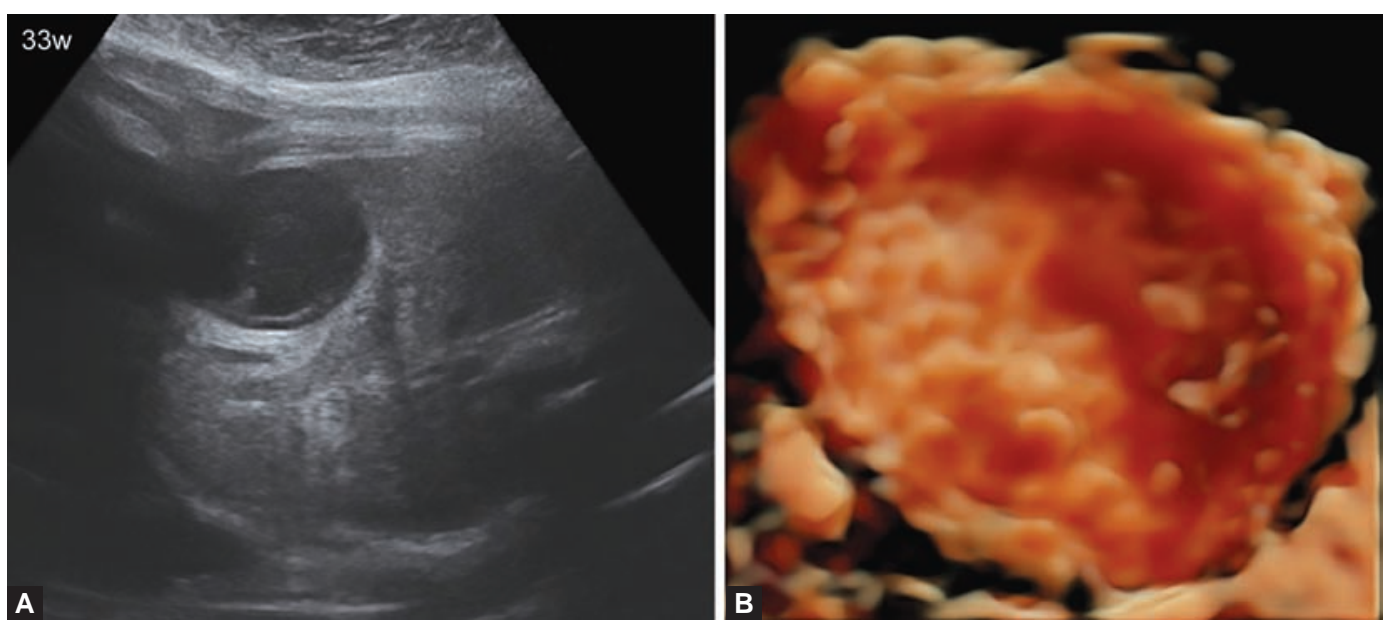

Figs 22A and B: HDlive image of a fetal enteric duplication cyst at 33 weeks of gestation: $(A)$ two-dimensional sonographic image and (B) HDlive image (Courtesy: Reprinted with permission from Hata T, et al) ${ }^{21}$

\section{Hydronephrosis}

On conventional 3D ultrasound reconstruction using the inversion mode, the dilated right renal pelvis is identified in relation to the stomach (Fig. 25A). Using 3D multiplanar and HDlive, the surface of the renal parenchyma, some of the calices, and dilated renal pelvis can easily be identified (Fig. 25B). The HDlive inversion mode realistically shows the anatomical relationship of the right renal pelvis with the spine and stomach (Fig. 26). 


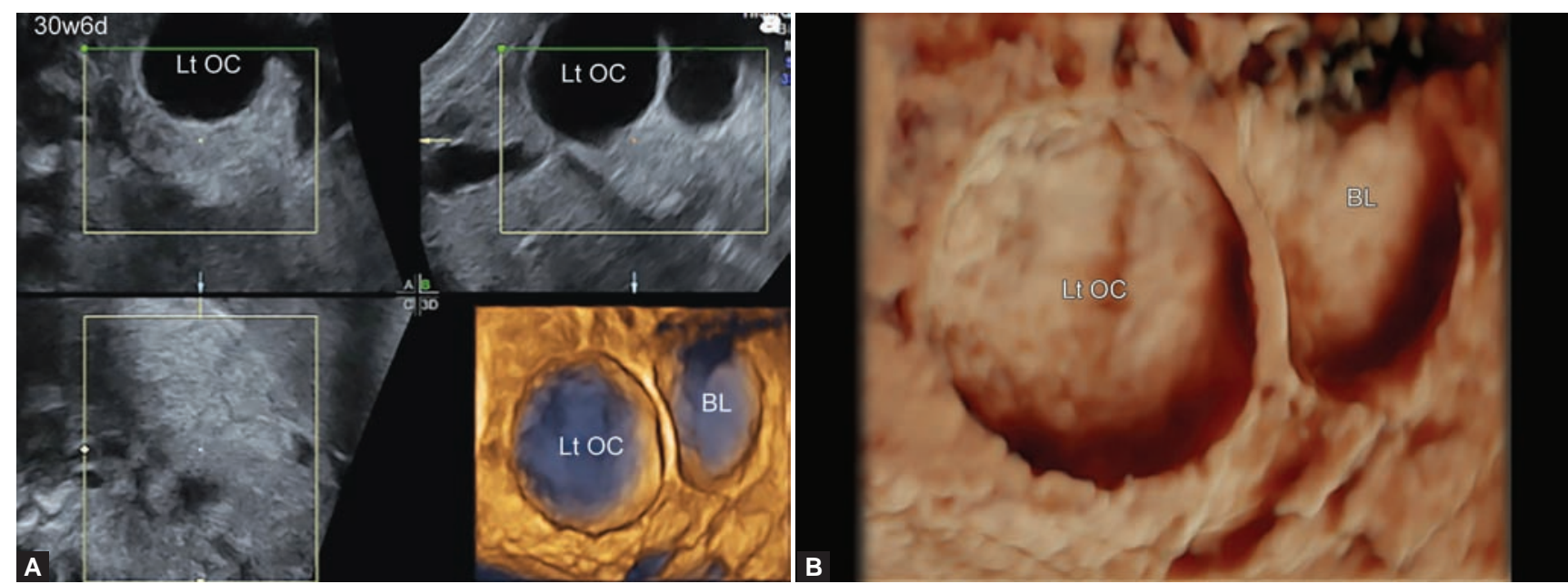

Figs 23A and B: HDlive image of a fetal ovarian cyst at 30 weeks and 6 days of gestation: (A) three-dimensional multiplanar image and (B) HDlive image (BL: Bladder; Lt OC: Left ovarian cyst)

\section{Multicystic Dysplastic Kidney}

2D sonography shows bilateral enlarged kidneys and multiple cysts (Fig. 27A). ${ }^{22}$ On the HDlive inversion mode, numerous randomly arranged rounded cysts form the left and right kidneys, and the umbilical vein and gallbladder are also observable (Figs 27B and C). The peripheral circular arrangement of the cysts that gives the 'necklace-like appearance' can be clearly identified (Figs 28A and B). ${ }^{22}$
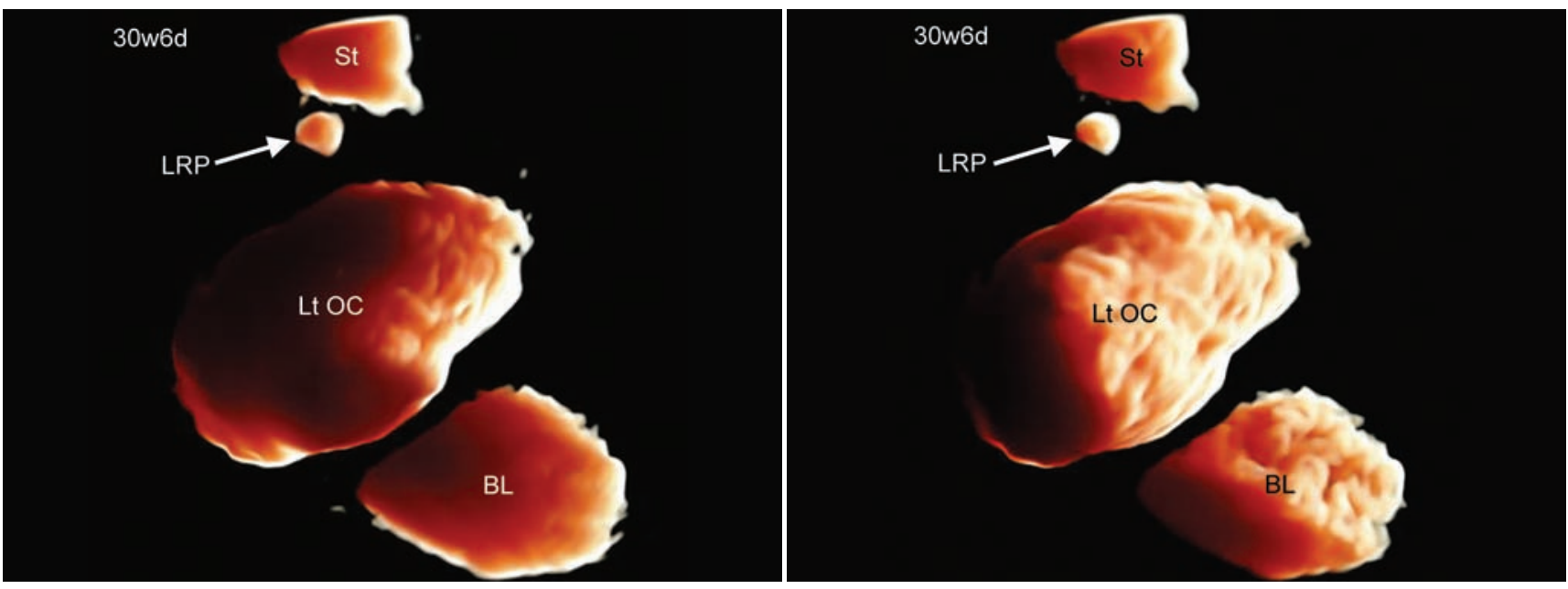

Fig. 24: HDlive images of a fetal abdomen using inversion mode and different light sources in a fetus with a left ovarian cyst at 30 weeks and 6 days of gestation (BL: Bladder; LRP: Left renal pelvis; Lt OC: Left ovarian cyst; St: Stomach)
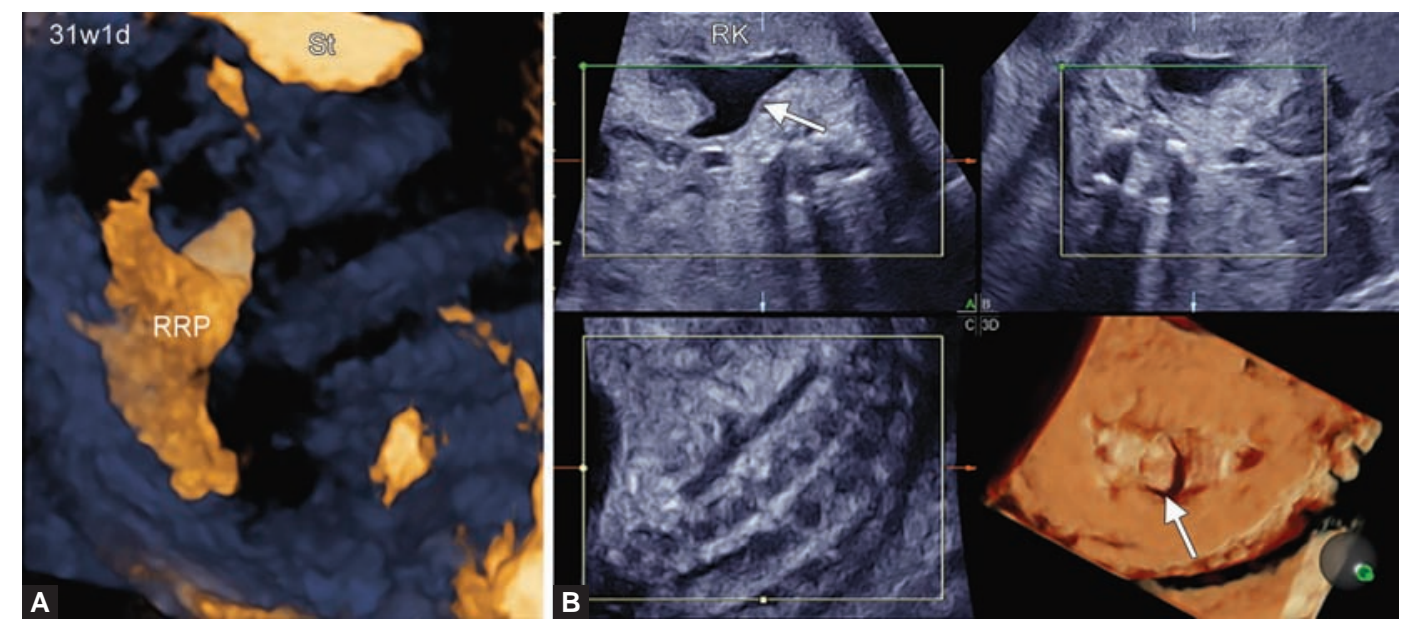

Figs 25A and B: HDlive image of a fetal abdomen with right hydronephrosis at 31 weeks and 1 day of gestation: (A) three-dimensional ultrasound image with the inversion mode and (B) three-dimensional multiplanar view and HDlive image. The neck of the pelvis is clearly visible (arrows) (RK: Right kidney; RRP: Right renal pelvis; St: Stomach) 

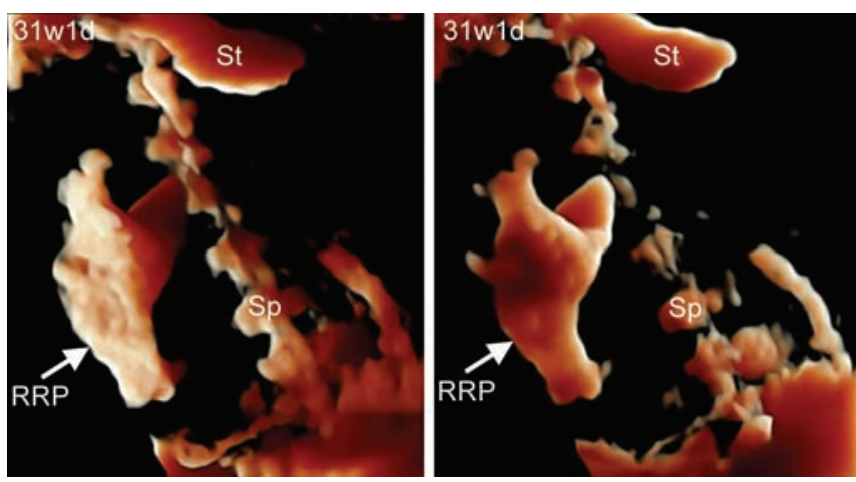

Fig. 26: HDlive images of a fetal abdomen using the inversion mode and different light sources in a fetus with right hydronephrosis at 31 weeks and 1 day of gestation (RRP: Right renal pelvis; Sp: Spine; St: Stomach)

\section{Persistent Cloaca}

Anatomical abnormalities on 2D sonography in a case of persistent cloaca (Figs 29A and B) ${ }^{23}$ are well-defined on HDlive. The bicornuate uterus with bilateral hydrosalpinx, and ascites are clearly identifiable, and its spatial relationship with the bladder, intestines, stomach, and gallbladder can also be recognized (Figs $29 \mathrm{C}$ and D). ${ }^{23}$

\section{Ascites}

Intra-abdominal organs in the peritoneal cavity can be clearly seen using HDlive (Fig. 30).

\section{Intra-abdominal Umbilical Vein Varix}

Focal dilatation is identified along the length of the intraabdominal umbilical vein on 2D sonography (Fig. 31A), and confirmed using 3D color Doppler (Fig. 31B). ${ }^{24}$ The dilated part can be clearly distinguished from the normal umbilical vein using the HDlive inversion mode (Figs 32A and B). Umbilical arteries can also be visualized.
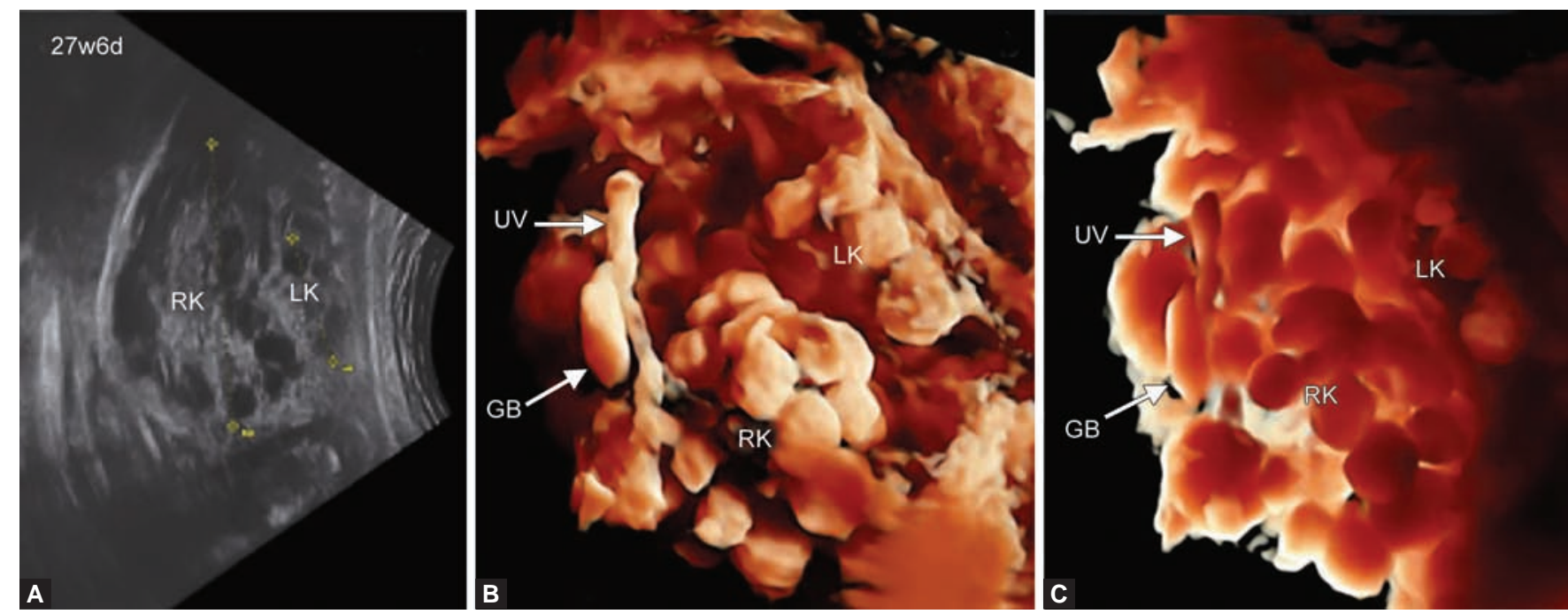

Figs 27A to C: HDlive images of a fetal abdomen using the inversion mode and different light sources in a fetus with a multicystic dysplastic kidney at 27 weeks and 6 days of gestation: (A) two-dimensional sonographic images (Courtesy: Reprinted with permission from Hata T, et al), ${ }^{22}$ (B and C) HDlive images with the inversion mode (GB: Gallbladder; LK: Left kidney; RK: Right kidney; UV: Umbilical vein)

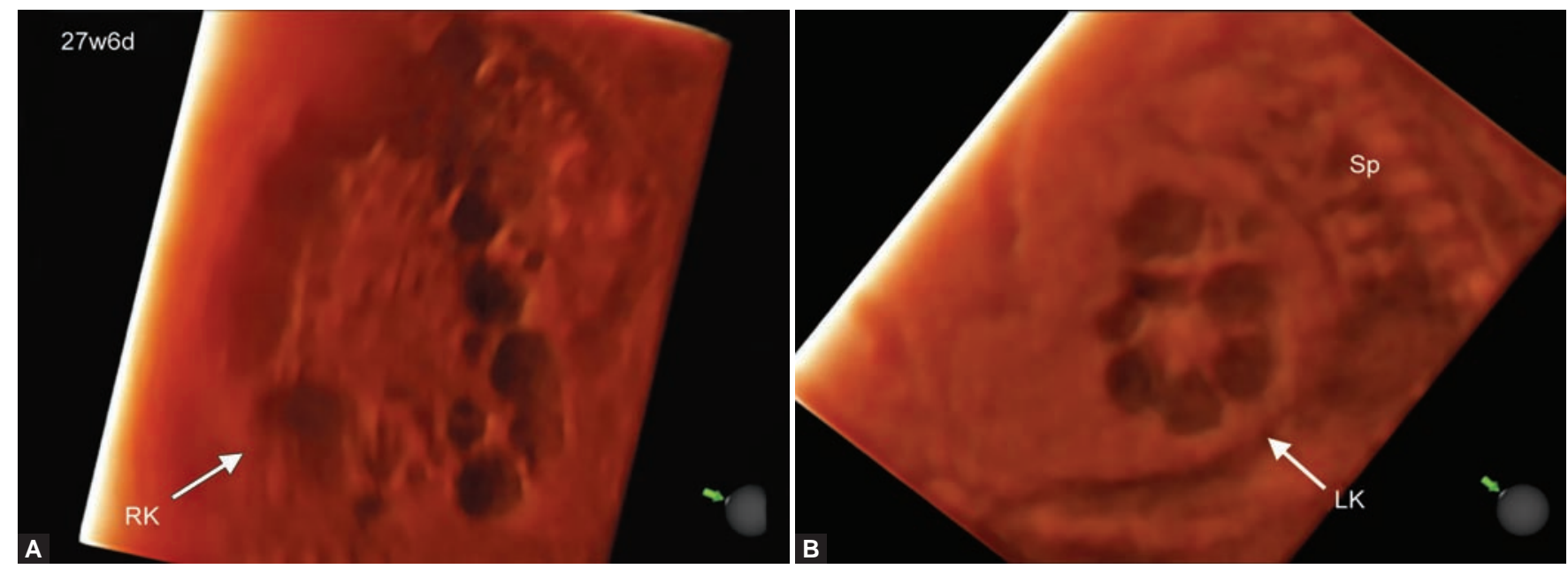

Figs 28A and B: HDlive cut-view images of fetal kidneys showing a necklace-like appearance in a fetus with a multicystic dysplastic kidney at 27 weeks and 6 days of gestation: (A) left kidney (LK) and (B) right kidney (RK) (Sp: Spine) (Courtesy: Reprinted with permission from Hata $T$, et al) ${ }^{22}$ 

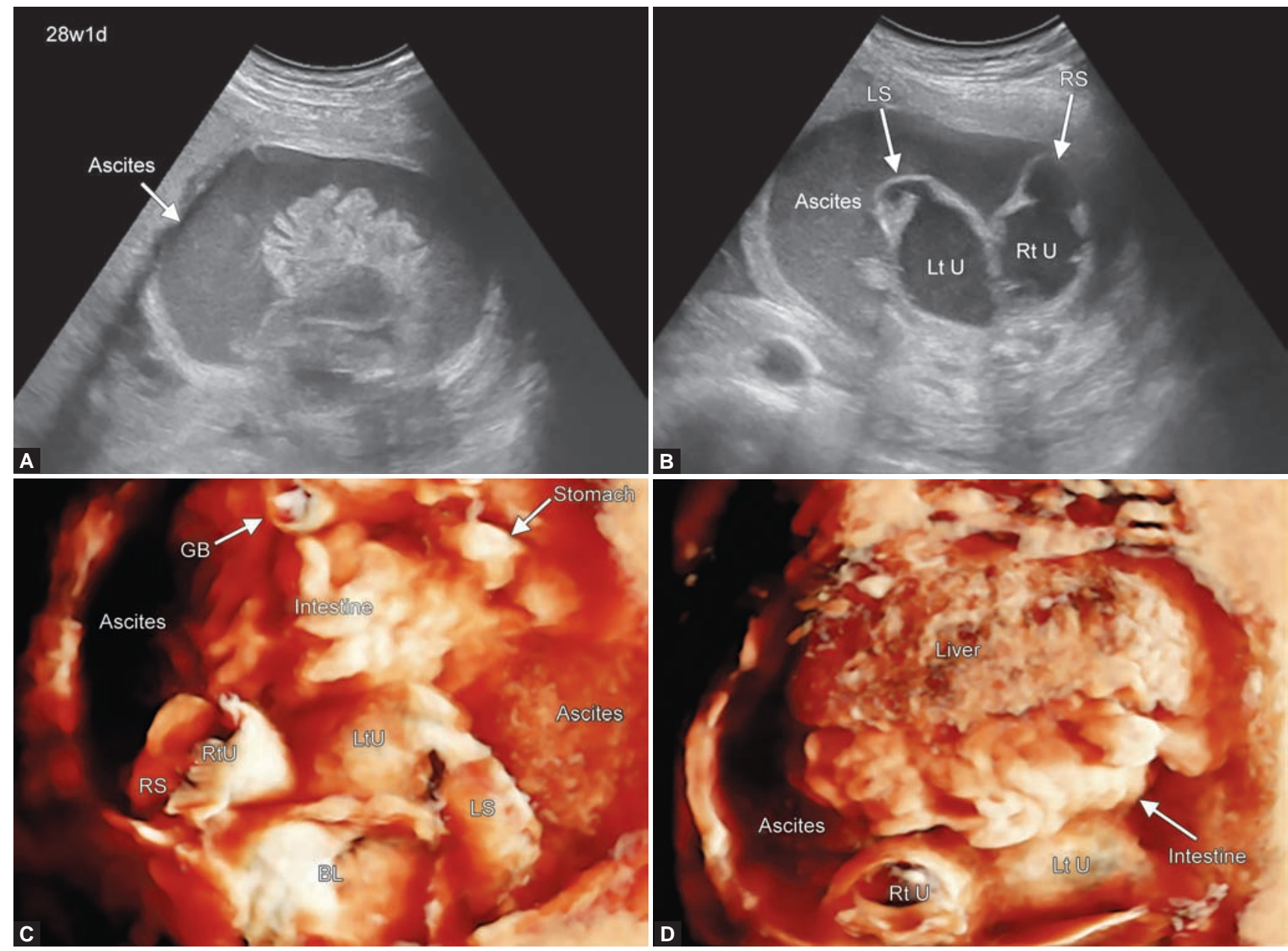

Figs 29A to D: HDlive images of a fetal abdomen with a persistent cloaca at 28 weeks and 1 day of gestation: (A and B) two-dimensional sonographic images, (C and D) HDlive images (BL: Bladder; GB: Gallbladder; LS: Left hydrosalpinx; Lt U: Left uterus; RS: Right hydrosalpinx; Rt U: Right uterus) (Courtesy: Reprinted with permission from Hata T, et al) ${ }^{23}$

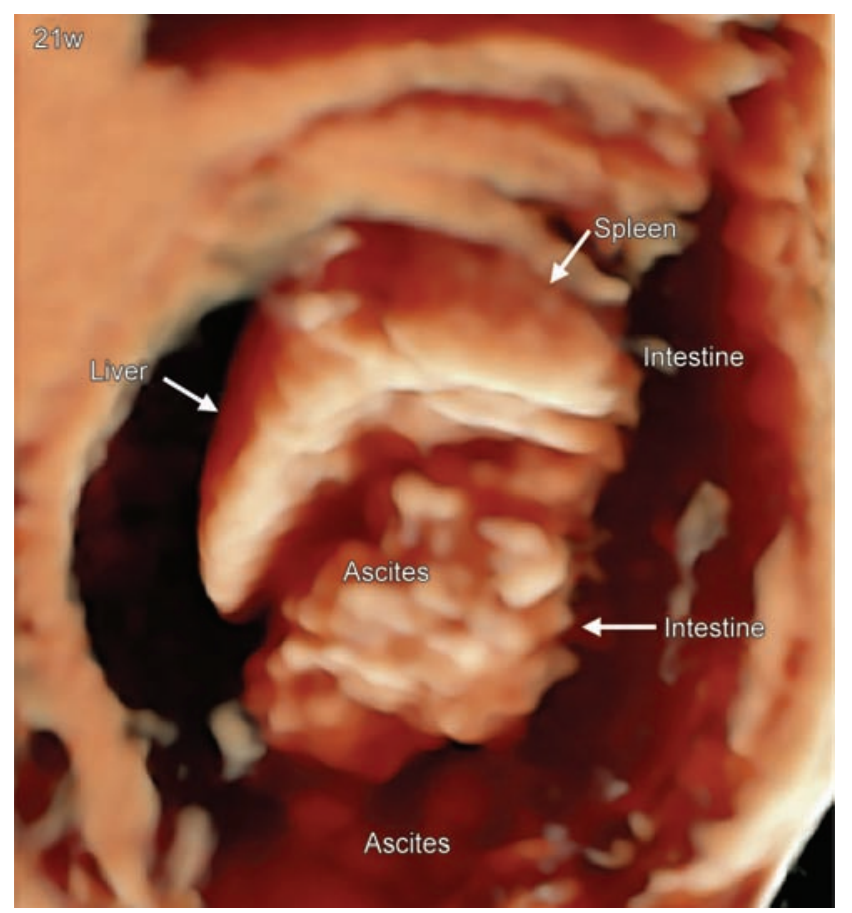

Fig. 30: HDlive image of a fetal abdomen with ascites at 21 weeks of gestation

\section{LIMITATIONS}

The operator must be well-trained in the reconstruction of ultrasound images using HDlive. It requires special skills and time to learn to be able to produce better quality images. Untrained physicians may not be able to obtain realistic images. Detailed knowledge of the normal anatomy is also important to differentiate it from anomalies. Some reported limitations of the surfacerendering mode are related to an unfavorable fetal position and hindrances such as the placenta, umbilical cord, or uterine wall, ${ }^{9}$ maternal or fetal movements, and an inadequate amniotic fluid volume. ${ }^{10}$ In the inversion mode, it is specific for fluid-filled structures and their adjacent tissues, ${ }^{25}$ so 'we could not obtain optimal images if fluid and tissue interfaces are not clearly delineated by ultrasound imaging. ${ }^{13}$ Mastering the use of the threshold filter tool is very valuable to produce quality images. Inappropriate application of the threshold filter will result in artifacts that may lead to false impressions. ${ }^{11}$ 


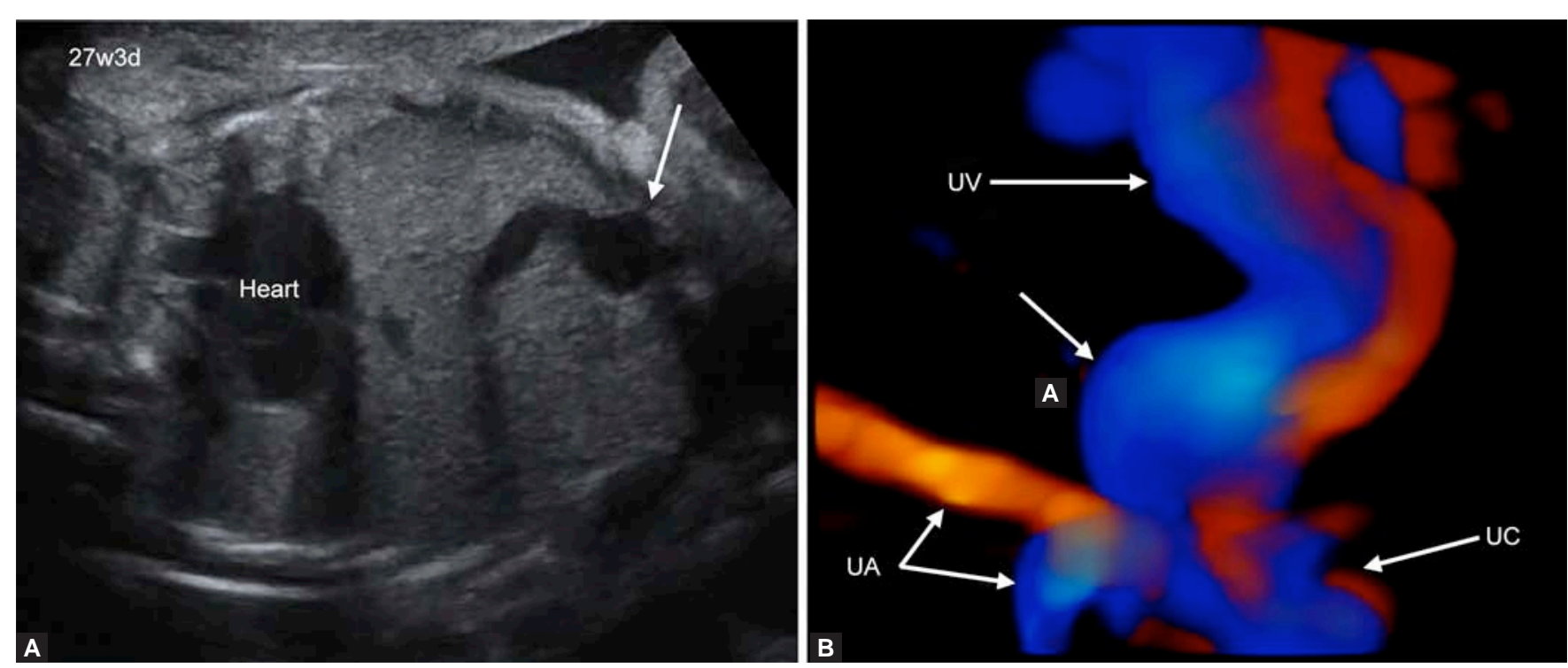

Figs 31A and B: Three-dimensional (3D) color Doppler image of a fetal abdomen with intra-abdominal vein varix (arrow) at 27 weeks and 3 days of gestation: (A) two-dimensional sonographic image and (B) 3D color Doppler image (UA: Umbilical artery; UC: Umbilical cord; UV: Umbilical vein)

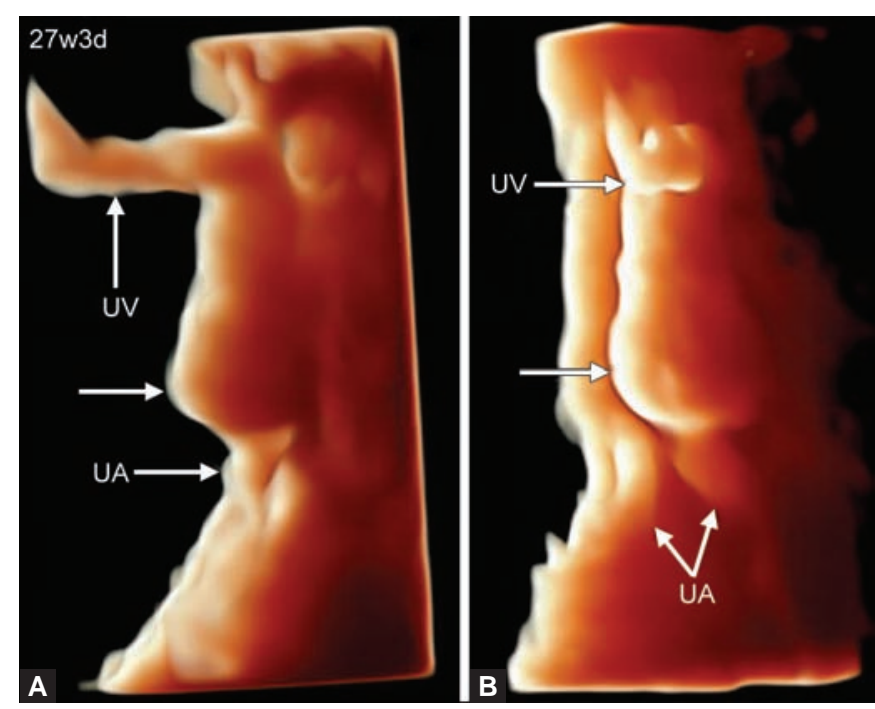

Figs $32 \mathrm{~A}$ and $\mathrm{B}$ : HDlive images of fetal intra-abdominal vein varix (arrows) using the inversion mode at 27 weeks and 3 days of gestation: (A) lateral view and (B) frontal view (UA: Umbilical artery; UV: Umbilical vein)

\section{CONCLUSION}

We presented different sonographic images of fetal intracranial, intrathoracic, and intra-abdominal anomalies evaluated with 2D sonography, and reconstructed images using HDlive. This review article focused on the advantages of using HDlive for those anomalies. From the early embryonic period, the HDlive inversion mode can be used to evaluate developing human brain vesicles. Anomalies can be diagnosed early in this stage by confirming differences from normality. Fetal intracranial anomalies are usually associated with a poor prognosis, and the use of HDlive can help the physician explain detailed information to the patient and family. The patient can easily understand the condition of her fetus and its severity because HDlive provides more humanlike features than black and white 2D or conventional 3D sonography. Fetal intrathoracic anomalies, which primarily involve the heart, remain the area of interest for clinical research. The use of HDlive, specifically the inversion mode, may give clinicians unique information on complex anomalies of the heart and great vessels even in early gestation. While fetal intra-abdominal anomalies are usually benign, they warrant strict surveillance because they may cause gradual or sudden complications. HDlive is useful in monitoring those lesions and probable complications that cannot be easily identified using conventional 2D sonography. Further use of this innovative tool in adjunct with 2D/3D/4D sonography is highly recommended to strengthen the advantages highlighted by previous studies. The use of HDlive for fetal intracranial, intrathoracic, and intra-abdominal anomalies brings us many more opportunities to give quality care to our patients and in the field of research.

\section{ACKNOWLEDGMENTS}

The work reported in this paper was supported by a Grant-in-Aid for Scientific Research on Innovative Areas 'Constructive Developmental Science' (No. 24119004), and a Research Grant (No. 25462561) from The Ministry of Education, Culture, Sports, Science and Technology, Japan.

\section{REFERENCES}

1. WHO (January, 2014) Congenital anomalies. Available at: http://www.who.int/mediacentre/factsheets/fs370/en/ (accessed on 3/1/2014). 
2. Kagan KO, Pintoffl K, Hoopmann M. First trimester ultrasound images using HDlive. Ultrasound Obstet Gynecol 2011;38(5):607.

3. Hata T. HDlive rendering image at 6 weeks of gestation. J Med Ultrasonics 2013;40(4):495-496.

4. Hata T, Mashima M, Ito M, Uketa E, Mori N. Threedimensional HDlive rendering images of the fetal heart. Ultrasound Med Biol 2013;39(8):1513-1517.

5. Hata T, Kanenishi K, Hanaoka U, Tanaka H. HDlive of the fetal heart. Donald School J Ultrasound Obstet Gynecol 2014;8(3):266-272.

6. Hata T, Hanaoka U, Tenkumo C, Sato M, Tanaka H, Ishimura $\mathrm{M}$. Three- and four-dimensional HDlive rendering images of normal and abnormal fetuses: pictorial essay. Arch Gynecol Obstet 2012;286(6):1431-1435.

7. Hata T, Hanaoka U, Mashima M. HDlive rendering image of cyclopia and a proboscis in a fetus with normal chromosomes at 32 weeks of gestation. J Med Ultrasonics 2014;41(1):109-110.

8. Hata T, Uketa E, Tenkumo C, Hanaoka U, Kanenishi K, TanakaH. Three- and four-dimensional HDlive rendering image of fetal acrania/exencephaly in early pregnancy. J Med Ultrasonics 2013;40(3):271-273.

9. Hanaoka U, Tanaka H, Koyano K, Uematsu R, Kanenishi K, Hata T. HDlive imaging of the face of fetuses with autosomal trisomies. J Med Ultrasonics 2014;41(3):339-341.

10. Grigore M, Mares A. The role of HDlive technology in improving the quality of obstetrical images. Med Ultrason 2013;15(3):209-214.

11. Lee W, Goncalves LF, Espinoza J, Romero R. Inversion mode. A new volume analysis tool for 3-dimensional ultrasonography. J Ultrasound Med 2005;24(2):201-207.

12. Souka AP, Nicolaides KH. Diagnosis of fetal abnormalities at the 10-14-week scan. Ultrasound Obstet Gynecol 1997;10(6): 429-442.

13. Hata T, Dai SY, Kanenishi K, Tanaka H. Three-dimensional volume-rendered imaging of embryonic brain vesicles using inversion mode. J Obstet Gynecol Res 2009;35(2):258-261.

14. Anselem O, Mezzetta L, Grange G, Zerah M, Benard C, Marcous V, Fallet-Bianco C, Adamsbaum C, Tsatsaris V. Fetal tumors of the choroid plexus: is differential diagnosis between papilloma and carcinoma possible? Ultrasound Obstet Gynecol 2011;38(2):229-232.
15. Ebrashy A. Controversial ultrasound findings in midtrimester pregnancy. Donald School J Ultrasound Obstet Gynecol 2011;5(2):151-157.

16. Gaglioti P, Oberto M, Todros T. The significance of fetal ventriculomegaly: etiology, short- and long-term outcomes. Prenat Diagn 2009;29(4):381-388.

17. Ghi T,Pilu G, Falco P, Segata M, Carletti A, Cocchi G, Santini D, Bonasoni P, Tanis G, Rizzo N. Prenatal diagnosis of open and closed spina bifida. Ultrasound Obstet Gynecol 2006;28(7): 899-903.

18. Babcook C, Chong B, Salamat MS, Ellis W, Goldstein R. Sonographic anatomy of the developing cerebellum: normal embryology can resemble pathology. Am J Roentgenol 1996; 166(2):427-433.

19. Uketa E, Hayashi K, Ito M, Sato M, Hata T. Three- and four-dimensional volume-rendered imaging of situs inversus totalis with inversion mode. Arch Gynecol Obstet 2012;286(2):533-535.

20. Mashima M, Tanaka H, Numoto A, Kubo H, Shimono R, Kusaka T, Itoh S, Hata T. Antenatal three-dimensional sonographic features of fetal biliary atresia. J Med Ultrasonics 2013;40(3):279-281.

21. Nishizawa C, Cajusay-Velasco S, Mashima M, Nobuhiro M, Hayashi K, Kubo H, Shimono R, Koyano K, Hata T. HDlive imaging of fetal enteric duplication cyst. J Med Ultrasonics 2014;41(4):511-514.

22. Tanaka T, Ito M, Uketa E, Mori N, Hanaoka U, Kanenishi K, Tanaka H, Hata T. Antenatal three-dimensional sonographic features of multicystic dysplastic kidney. J Med Ultrasonics 2013;40(2):181-183.

23. Ishibashi M, Tanaka H, Ito M, Uketa E, Mori N, Hanaoka U, Kanenishi K, Hata T. Antenatal three-dimensional sonographic diagnosis of persistent cloaca. J Med Ultrasonics 2013;40(3):275-277.

24. Austria B, Hanaoka U, Sato M, Hata T. Three- and fourdimensional sonographic diagnosis of fetal intra-abdominal umbilical vein varix. J Med Ultrasonics 2014;41(2):245-246.

25. Hata T, Tanaka H, Noguchi J, Dai SY, Yamaguchi M, Yanagihara T. Four-dimensional volume-rendered imaging of the fetal ventricular outflow tracts and great arteries using inversion mode for detection of congenital heart disease. J Obstet Gynecol Res 2010;36(3):513-518. 